University of Nebraska - Lincoln

DigitalCommons@University of Nebraska - Lincoln

2006

\title{
The dissolution of synthetic Na-boltwoodite in sodium carbonate solutions
}

Eugene S. Ilton

Pacific Northwest National Laboratory, Eugene.Ilton@pnl.gov

Chongxuan Liu

Pacific Northwest National Laboratory, chongxuan.liu@pnl.gov

Wassana Yantasee

Pacific Northwest National Laboratory

Zheming Wang

Pacific Northwest National Laboratory, Zheming.wang@pnl.gov

Dean A. Moore

Pacific Northwest National Laboratory, dean.moore@pnl.gov

See next page for additional authors

Follow this and additional works at: https://digitalcommons.unl.edu/usdoepub

Part of the Bioresource and Agricultural Engineering Commons

Ilton, Eugene S.; Liu, Chongxuan; Yantasee, Wassana; Wang, Zheming; Moore, Dean A.; Felmy, Andrew R.; and Zachara, John M., "The dissolution of synthetic Na-boltwoodite in sodium carbonate solutions" (2006). US Department of Energy Publications. 268.

https://digitalcommons.unl.edu/usdoepub/268

This Article is brought to you for free and open access by the U.S. Department of Energy at DigitalCommons@University of Nebraska - Lincoln. It has been accepted for inclusion in US Department of Energy Publications by an authorized administrator of DigitalCommons@University of Nebraska - Lincoln. 


\section{Authors}

Eugene S. Ilton, Chongxuan Liu, Wassana Yantasee, Zheming Wang, Dean A. Moore, Andrew R. Felmy, and John M. Zachara 


\title{
The dissolution of synthetic Na-boltwoodite in sodium carbonate solutions
}

\author{
Eugene S. Ilton *, Chongxuan Liu, Wassana Yantasee, Zheming Wang, \\ Dean A. Moore, Andrew R. Felmy, John M. Zachara \\ Pacific Northwest National Laboratory, Chemical Sciences Division, 902 Battelle Boulevard, MS K8-96, Richland, WA 99352, USA
}

Received 10 November 2005; accepted in revised form 15 June 2006

\begin{abstract}
Uranyl silicates such as uranophane and Na-boltwoodite appear to control the solubility of uranium in certain contaminated sediments at the US Department of Energy Hanford site [Liu, C., Zachara, J.M., Qafoku, O., McKinley, J.P., Heald, S.M., Wang, Z. 2004. Dissolution of uranyl microprecipitates in subsurface sediments at Hanford Site, USA. Geochim. Cosmochim. Acta 68, 45194537.]. Consequently, the solubility of synthetic $\mathrm{Na}$-boltwoodite, $\mathrm{Na}\left(\mathrm{UO}_{2}\right)\left(\mathrm{SiO}_{3} \mathrm{OH}\right) \cdot 1.5 \mathrm{H}_{2} \mathrm{O}$, was determined over a wide range of bicarbonate concentrations, from circumneutral to alkaline $\mathrm{pH}$, that are representative of porewater and groundwater compositions at the Hanford site and calcareous environments generally. Experiments were open to air. Results show that Na-boltwoodite dissolution was nearly congruent and its solubility and dissolution kinetics increased with increasing bicarbonate concentration and $\mathrm{pH}$. A consistent set of solubility constants were determined from circumneutral $\mathrm{pH}(0$ added bicarbonate) to alkaline $\mathrm{pH}(50 \mathrm{mM}$ added bicarbonate). Average $\log K_{\mathrm{sp}}^{\mathrm{o}}=5.86 \pm 0.24$ or $5.85 \pm 0.0 .26$; using the Pitzer ion-interaction model or Davies equation, respectively. These values are close to the one determined by [Nguyen, S.N., Silva, R.J., Weed, H.C., Andrews, Jr., J.E., 1992. Standard Gibbs free energies of formation at the temperature $303.15 \mathrm{~K}$ of four uranyl silicates: soddyite, uranophane, sodium boltwoodite, and sodium weeksite. J. Chem. Thermodynamics 24, 359-376.] under very different conditions ( $\mathrm{pH} 4.5$, Ar atmosphere).

(c) 2006 Elsevier Inc. All rights reserved.
\end{abstract}

\section{Introduction}

Uranium contamination of groundwater and soils at United States Department of Energy (DOE) sites poses a significant challenge for predicting uranium reactive transport and designing remediation strategies (Riley and $\mathrm{Za}-$ chara, 1992). The challenge arises, in part, from the complicated chemical behavior of the uranyl ion which readily forms complexes with a variety of ligands (Grenthe et al., 1992). This, in turn, affects $U(V I) / U(I V)$ redox potentials, uranyl adsorption behavior, and the stability of various uranyl containing mineral phases. Most uranyl minerals adopt a sheet like structure, but uranyl can form an astonishing array of minerals due to its ability to polymerize and bond with ligands along its equatorial plane (Burns

\footnotetext{
${ }^{*}$ Corresponding author.

E-mail address: Eugene.Ilton@pnl.gov (E.S. Ilton).
}

et al., 1996). Common ligands in the environment that complex with uranyl and form stable uranyl solid phases include hydroxyl, phosphate, carbonate, and silicate (see reviews by Burns et al., 1996; and Burns and Finch, 1999). In silica rich environments, uranyl silicates are important secondary products of the oxidative weathering of $\mathrm{UO}_{2(\mathrm{~s})}$ that control uranium release into the environment. Consequently, there have been a number of studies on uranyl silicate solubility, including soddyite (Nguyen et al., 1992; Perez et al., 1997; Giammar and Hering, 2002), uranophane (Nguyen et al., 1992; Perez et al., 2000), Na-weeksite (Nguyen et al., 1992), and Na-boltwoodite (Nguyen et al., 1992).

Uranyl silicates can also form when uranyl directly seeps into sediments. At the US DOE Hanford site, high level radionuclide tank waste at $80^{\circ} \mathrm{C}$ containing $0.3 \mathrm{~mol} / \mathrm{L}$ uranyl and $2.5 \mathrm{~mol} / \mathrm{L} \mathrm{Na}-\mathrm{HCO}_{3}$ (along with other contaminants) leaked into vadose zone sediments containing a high abundance of silicates such as quartz, feldspar, and 
phyllosilicates (Serne et al., 2002). Characterization of the contaminated sediments with X-ray absorption spectroscopy, laser induced fluorescence spectroscopy, and electron microscopy/microprobe indicated that uranium was present as a sodium uranyl silicate microprecipitate (Mckinley et al., 2002; Catalano et al., 2004; Wang et al., 2005). Liu et al. (2004) showed that pore waters at Hanford were closest to saturation with respect to Na-boltwoodite. Liu et al. (2004) also measured the kinetics and extent of uranyl dissolution using contaminated vadose zone sediments from Hanford and showed that the solubility of U more closely matched Na-boltwoodite than other uranyl silicates. That study, however, found that above $\mathrm{pH} \mathrm{8.2,} \mathrm{the} \mathrm{measured}$ solubility increasingly diverged from the calculated solubility of all uranyl silicates, including Na-Boltwoodite, with increasing $\mathrm{pH} /$ carbonate. Further, in some samples, steady state concentrations were never attained, despite nearly 200 days of reaction. Liu et al. (2004) showed that uranyl diffusion in microfractures could account for the apparent slow dissolution kinetics. Nonetheless, the convolution of diffusion controlled processes with solubility kinetics made it difficult to assess with certainty what phase was controlling uranium solubility and whether the apparent dissolution kinetics was diffusion or solubility controlled. Given the uncertainties inherent in the $K_{\mathrm{sp}}^{\mathrm{o}}$ (Na-boltwoodite) in Nguyen et al. (1992) - i.e., only one determination at $\mathrm{pH} 4.5$, with soddyite precipitation, and expressed as a minimum $K_{\mathrm{sp}}^{\mathrm{o}}$ - there is a need to re-determine the solubility of $\mathrm{Na}$ boltwoodite under a broader set of conditions that minimize the chance for secondary precipitate formation.

In this contribution, we evaluated the solubility of a synthetic Na-boltwoodite, $\mathrm{Na}\left(\mathrm{UO}_{2}\right)\left(\mathrm{SiO}_{3} \mathrm{OH}\right) \cdot 1.5 \mathrm{H}_{2} \mathrm{O}$, over a range of bicarbonate concentrations that are representative of pore water compositions at Hanford. This study complements work already done on soddyite and uranophane solubility as a function of bicarbonate (Perez et al., 1997; Perez et al., 2000). Equilibrium was approached from undersaturation in continually stirred batch reactors. Solid/solution ratios were varied to provide alternative tests for nearness of approach to equilibrium. A subset of samples was pretreated with high bicarbonate solutions in order to evaluate potential minor contamination from a U(VI)-rich, Si-deficient phase. The results provide greater constraints on distinguishing chemical and physical controls on the reactive transport of uranium at Hanford and other locations where uranyl silicates may precipitate.

\section{Materials and methods}

\subsection{Synthesis of Na-boltwoodite}

Na-boltwoodite was synthesized with reagent grade or better chemicals following the procedure of Honea (1961) and Nguyen et al. (1992). Briefly, stoichiometric proportions of uranyl acetate dihydrate and sodium metasilicate nonahydrate (Sigma) were mixed at room temperature under an argon atmosphere. The solution $\mathrm{pH}$ was adjusted to 10.5 using carbonate free $0.1 \mathrm{~mol} / \mathrm{L} \mathrm{NaOH}$ (Biopham Inc., AR). The solution was stirred at room temperature for $2 \mathrm{~h}$ under argon atmosphere before being refluxed at $90^{\circ} \mathrm{C}$ for $24 \mathrm{~h}$ outside the argon chamber. The suspension was filtered and the solid was rinsed with boiling deionized (DI) water to remove excess starting materials. The solid was then vacuum-dried. The dried, homogenized solid (ca. $5 \mathrm{~g}$ ) was then cooked with $70 \mathrm{~mL}$ deionized water at $150{ }^{\circ} \mathrm{C}$ in a Teflonlined $125 \mathrm{~mL}$ Parr bomb (model 4748, Parr Instrument Co.) for 7 days. The suspension was filtered, rinsed with warm DI water, vacuum-dried, and stored at room temperature. BET analysis yielded a surface area $30.78 \mathrm{~m}^{2} / \mathrm{g}$.

\subsection{Analytical methods}

Solution compositions were determined with an inductively coupled plasma-atomic emission spectrometer, ICPAES, (Atomscan 25, Thermal Jarrel Ash). The detection limits for $\mathrm{U}(\mathrm{aq})$ and $\mathrm{Si}(\mathrm{aq})$ were 0.4 and $1.8 \mu \mathrm{M}$, respectively. $\mathrm{pH}$ was recorded with a Beckman PHI 71 (three decimal) $\mathrm{pH}$ meter and Orion glass body combination $\mathrm{pH}$ probe. Solids were characterized with powder X-ray diffraction (XRD), high resolution transmission electron microscopy (HRTEM), laser induced fluorescence spectroscopy (LIFS), and X-ray photoelectron spectroscopy (XPS).

Powder XRD analyses were obtained with a Philips AMR focusing monochromator equipped with a Philips scintillation detector. $\mathrm{Cu} \mathrm{Ka}$ radiation with a typical wavelength of $0.15405 \mathrm{~nm}$ was used to obtain the XRD patterns.

LIFS measurements of the uranyl silicate samples were performed in a Cryo Industries RC-152 cryostat at $5.5 \pm 1.0 \mathrm{~K}$, which is near liquid He-temperature (Wang et al., 2004). Each solid sample was mounted in a custom-built sealed copper sample holder fitted with a sapphire optical window. Inside the cryostat, the sample was directly exposed to the vapor flow of liquid helium. The fluorescence emission spectra of samples were obtained by excitation at $415 \mathrm{~nm}$ with the frequency doubled output of a Spectra-Physics Nd:YAG laser pumped MOPO-730 laser and the resulting fluorescence was collected at an Acton SpectroPro 300i double monochromator spectrograph.

Transmission electron microscopic analyses were performed on a JEOL JEM 2010 microscope with a pointto-point resolution of $0.194 \mathrm{~nm}$. The microscope has a $\mathrm{LaB}_{6}$ filament and operates at $200 \mathrm{KeV}$. All images were digitally recorded with a slow scan charge couple device (CCD) camera (image size, $1024 \times 1024$ pixels). Energy dispersive X-ray spectroscopy (EDS) compositional analysis of the specimen was carried out using a SiLi ( $\mathrm{Li}$ drifted Si) detector of an Oxford Link system with ISIS analysis software. Quantification of the spectra was based on a theoretical cross section and an absorption correction was not considered due to the thin section of specimen.

XPS analyses were performed with a Scienta ESCA-300, which employs a high flux of monochromatic Al $\mathrm{K} \alpha \mathrm{X}$ rays. The analyzer operating parameters of $150 \mathrm{eV}$ pass 
energy and a $0.8 \mathrm{~mm}$ slit yielded a Fermi level width $0.38 \mathrm{eV}$ for $\mathrm{Ag}^{\circ}$. A monochromatic low-energy electron flood gun was used to help neutralize charge build up at the sample surface. Spectra were acquired at a $90^{\circ}$ takeoff angle and consisted of high-resolution regional scans over line positions of the elements of interest. Angle-resolved analyses were not possible, due to surface roughness. The analytical area was about $3 \mathrm{~mm} \times 160 \mu \mathrm{m}$ and the information depth (95\% of signal) was approximately $60 \AA$. U, Si, and $\mathrm{O}$ were measured with the U4f, Si2s, Si2p, and O1s peaks. The Si2s line was used for compositional analysis because U5d interfered with Si2p. However, the binding energy (BE) of Si2p was still informative. Analyses were semi-quantified using $\mathrm{Al} \mathrm{K} \alpha$ photoionization cross sections as first-order sensitivity factors (Scofield, 1976). The same background fitting procedure was used for each element from sample to sample: linear (Si2s) or Shirley background $\left(\mathrm{U}_{4} \mathrm{f}_{7 / 2}\right)$. This method is sufficient for obtaining relative differences in U/Si atomic ratios between samples, not necessarily absolute elemental ratios. Peak positions were referenced to the $\mathrm{BE}$ of $\mathrm{C} 1 \mathrm{~s}$ at $285 \mathrm{eV}$.

Sample preparation for XPS was performed under argon in a glove box. Slurries of reacted boltwoodite were poured onto supported alumina membranes $(0.02 \mu \mathrm{m}$ Anodisc) and excess solution was vacuumed off. Deionized water at $\mathrm{pH} 7$ (no carbonate) was then poured over the sample and quickly vacuumed away. Samples were prepared as powders, in chip form, and in one case left as a consolidated film on the alumina membrane. The powders and chips were then gently pressed into double sided carbon tape, backed by centimeter-sized aluminum sheets. Samples that remained on the filter paper did not need to be pressed as they were sufficiently consolidated.

Because boltwoodite is an electrical insulator, charge broadening and distortion of spectral lines during XPS analysis is an issue. The instrument in this study employs a monochromatic X-ray beam and required the use of a low-energy electron flood gun to help charge-neutralize the samples. It is well-known that hexavalent $U$ tends to reduce during XPS analysis. Although determining oxidation state was not a necessary goal, beam induced reduction would lower peak to background ratios and would also redistribute spectral intensity into new satellites associated with the $5^{+}$and $4^{+}$valence states. Both phenomena would make precise determinations of U/Si more difficult. Consequently, we minimized and standardized exposure of the samples to the X-ray beam. Fortunately, sequential measurements indicated that little to no beam induced reduction occurred during analysis.

\subsection{Dissolution experiments}

Dissolution experiments were conducted for 7 days at $23 \pm 2{ }^{\circ} \mathrm{C}$ under batch reactor conditions. Samples $(0.25 \mathrm{~g})$ of synthetic sodium boltwoodite were reacted with $100 \mathrm{~mL}$ of solution in $250 \mathrm{~mL}$ HDPE square bottles (Nalgene) containing different concentrations of $\mathrm{NaHCO}_{3}$
(Aldrich, ACS grade). Sodium concentrations were held constant at $50 \mathrm{mM}$ with addition of $\mathrm{NaNO}_{3}$ (Fisher Scientific, ACS certified). The suspensions were well mixed, using an orbital shaker, and in contact with atmospheric carbon dioxide. At select times, suspension $\mathrm{pH}$ was measured and solution samples were drawn and passed through $0.2 \mu \mathrm{m}$ Teflon filters. The first $1 \mathrm{~mL}$ of each sample was discarded to minimize the potential effect from adsorption of uranium/silica on the filters. The collected sample $(4 \mathrm{~mL})$ was acidified with $25 \mu \mathrm{L}$ of concentrated doubled distilled nitric acid (GFS Chemicals).

Three types of experiments were performed and are referred to as (1) kinetic experiments, (2) 7-day experiments, and (3) pretreated experiments. For the kinetic experiments, dissolution kinetics were followed at $0.1,0.3,1.2$, 6 , and $50 \mathrm{mM}$ added $\mathrm{NaHCO}_{3}$. Additional kinetic experiments were performed at $50 \mathrm{mM} \mathrm{NaHCO}_{3}$ using 0.5 , 0.75 , and $1 \mathrm{~g} / 100 \mathrm{~mL}$ solid/solution ratios. These experiments put further constraints on the approach to equilibrium by testing the effect of increasing solid surface area on attainment of steady state conditions.

The 7-day experiments were only sampled at the conclusion of the experiments (i.e., after 7 days), but were performed at a greater number of added bicarbonate values (i.e., $0,0.1,0.3,0.6,1.2,3.5,6,12,20,30$, and $50 \mathrm{mM}$ $\mathrm{NaHCO}_{3}$ ). These experiments provided a more complete assessment of the effect of bicarbonate concentration on Na-boltwoodite solubility and also provided a check on the possibility that periodic sampling of the kinetic experiments might have introduced systematic errors. Each experiment was performed in duplicate.

The pretreated experiments, a subset of the kinetic experiments, used starting material that was preleached with a $50 \mathrm{mM}$ bicarbonate solution for $24 \mathrm{~h}$. These experiments were only performed at $1.2,6$, and $50 \mathrm{mM}$ added bicarbonate. The objective was to assess the possibility that the starting material was contaminated with a minor amount of a U-rich, Si-deficient phase that was not Naboltwoodite.

\section{Results}

\subsection{Characterization of synthetic sodium boltwoodite}

XRD results (data not shown) are consistent with Naboltwoodite synthesized by Nguyen et al. (1992), but we cannot categorically rule out minor impurities with this method. Our XRD pattern does contain a few additional lines of minor intensity compared to Nguyen et al., but it is difficult to unambiguously attribute them to a particular phase. The lack of a true standard for sodium boltwoodite (natural end-member Na-boltwoodite has not been isolated) and orientation issues renders XRD less than ideal for characterization. For example, relative intensities were a strong function of sample preparation method (packed powder versus powder smear mount) and even varied significantly between duplicate mounts using the same 
method. Further characterizations were done with bulk dissolution analysis, TEM, XPS, and LIFS.

TEM micrographs describe well-faceted blade-like platelets/needles of the solid phase (Fig. 1). EDS analyses of individual particles yield $\mathrm{Si} / \mathrm{U}=0.95 \pm 0.047(1 \sigma)$ which is within error of the stoichiometric ratio of $1: 1$ expected for boltwoodite. Na concentrations were consistently lower than stoichiometric values and highly variable; however, it is well-known that alkali cations are mobile under the electron beam. Minor Al was recorded, and might have been introduced with the metasilicate nanohydrate used in the synthesis. In sum, TEM observations are consistent with the presence of a single phase.

Bulk dissolution of the synthetic material in $2 \%$ by volume of nitric acid yielded $\mathrm{U} / \mathrm{Si}=1.011 \pm 0.014(1 \sigma$, four duplicates), $\mathrm{U} / \mathrm{Na}=1.039 \pm 0.020(1 \sigma$, four duplicates), and only trace $\mathrm{Ca}$ and $\mathrm{K}$. The bulk analyses are consistent with stoichiometric Na-boltwoodite, given that some variation in $\mathrm{Na}$ concentration and degree of hydration is possible but should not affect the structure appreciably.

Fig. 2 shows U4f and O1s XPS spectra for unreacted Na-boltwoodite. Note the satellites at 4 and $10 \mathrm{eV}$ above the main $\mathrm{U} 4 \mathrm{f}$ lines, which are typical of $\mathrm{U}^{6+}$. The $\mathrm{BE}$ for the $\mathrm{U}_{4 \mathrm{f}_{7 / 2}}$ peak is $382.15 \mathrm{eV}$, which is consistent with $\mathrm{U}_{4} \mathrm{f}_{7 / 2}$ BEs for $\mathrm{U}^{6+}$ compounds (e.g., we measured the $\mathrm{BE}$ of $\mathrm{U}_{4 \mathrm{f}_{7 / 2}}$ for schoepite at $382.2 \mathrm{eV}$ ). The full-widthat-half maximum (FWHM) of the $\mathrm{U}_{4} \mathrm{f}_{7 / 2}$ peak is $1.17 \mathrm{eV}$, which indicates excellent charge compensation and is consistent with one predominant bonding environment for $\mathrm{U}$. The oxygen region shows three peaks that were fitted with Gaussians; a peak at $530.7 \mathrm{eV}$ that corresponds to oxide, a broad peak centered at $532.3 \mathrm{eV}$ that records a mixture of hydroxyl and bound $\mathrm{H}_{2} \mathrm{O}$, and a shallow peak at $536 \mathrm{eV}$ that is a Na Auger line. Curve fitting yields $\left(\mathrm{OH}+\mathrm{H}_{2} \mathrm{O}\right) /$ $\mathrm{O}($ total $)=0.3$, which is close to the ideal ratio of 0.33

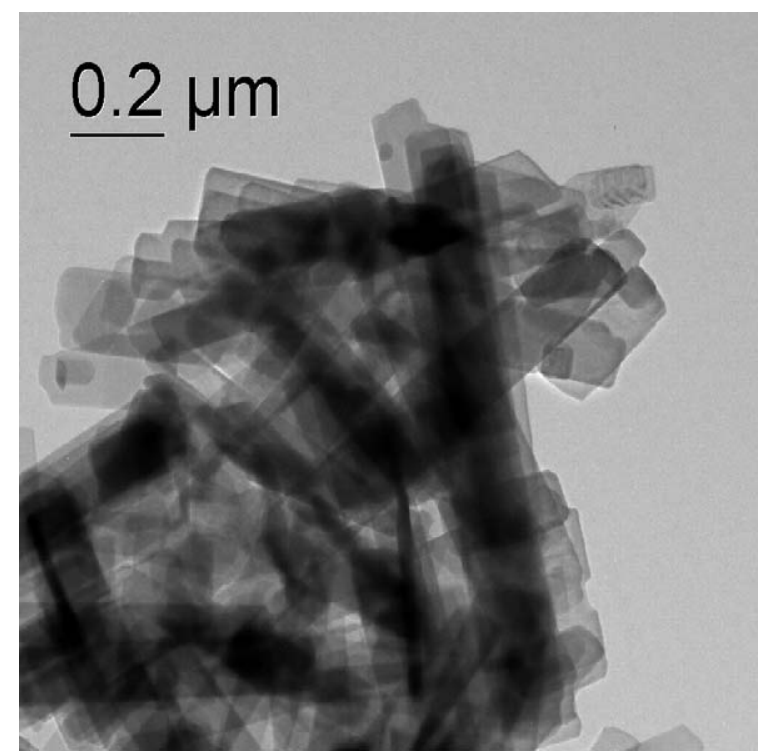

Fig. 1. HRTEM micrograph of the synthetic material.
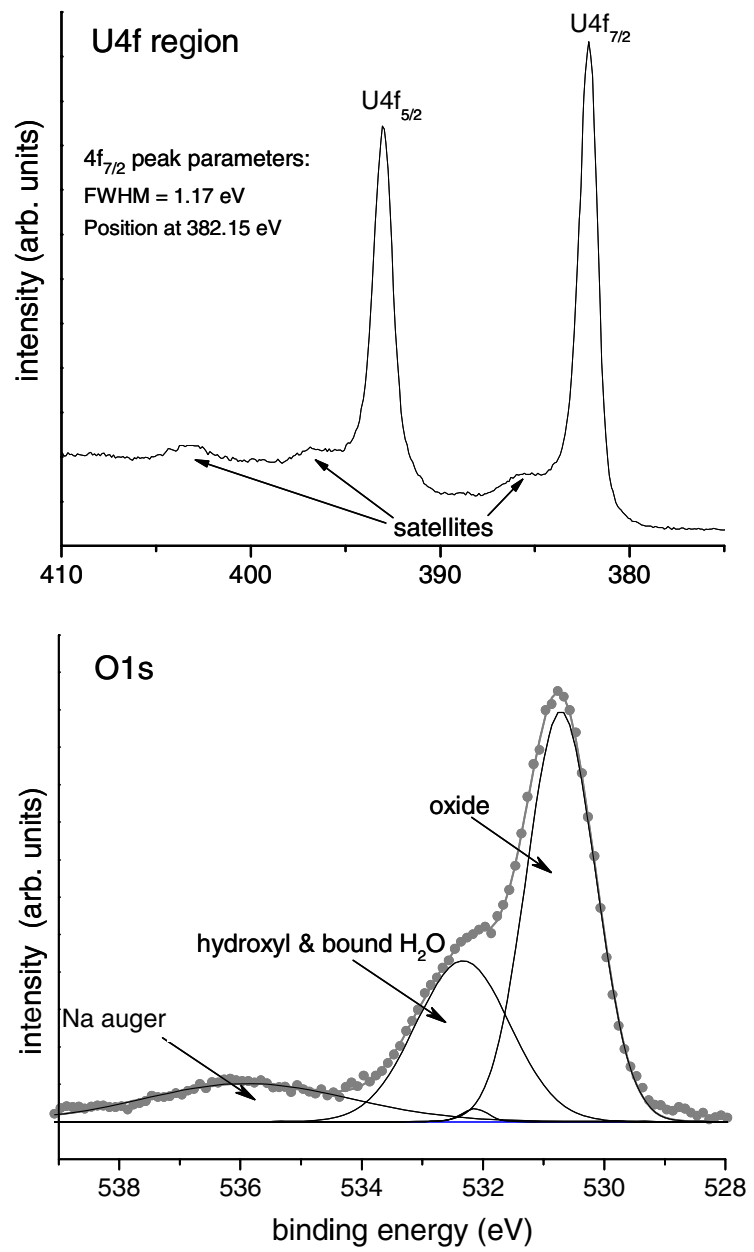

Fig. 2. XPS of the unreacted synthetic material. The top figure shows the $\mathrm{U} 4 \mathrm{f}$ region and the bottom figure shows the $\mathrm{O} 1 \mathrm{~s}$ region.

(e.g., Vochten et al., 1997). The small peak at $\sim 532 \mathrm{eV}$ accounts for about $1 \%$ missing intensity. It could simply represent some asymmetry in one of the main peaks and is too small to attribute to a third oxygen species. The BEs of Si2p and Si2s are 101.2 and $152.8 \mathrm{eV}$, respectively, which are appreciably lower than for framework silicates ( $\sim 103.5$ and $\sim 154.5 \mathrm{eV}$, personal data) and phyllosilicates ( $\sim 102.5$ and $\sim 153.6$, personal data). Olivine, a nesosilicate, has Si2s at $\sim 153 \mathrm{eV}$ (online NIST XPS data base), near the value for synthetic Na-boltwoodite. It is well-known that the BEs of $\mathrm{Si}$ systematically increase with increasing $\mathrm{SiO}_{4}$ polymerization. Indeed, the measured BEs for Si2s and $\mathrm{Si} 2 \mathrm{p}$ indicate that $\mathrm{Si}$ is non-polymerized in the near-surface region (top $\sim 60 \AA$ ) of the synthetic material. This is consistent with the bulk structure of boltwoodite. The measured $\mathrm{U} / \mathrm{Si}$ ratio is 0.83 , which cannot be considered accurate as we used Scofield ionization cross sections as first order sensitivity factors. Development of an empirical sensitivity factor for $\mathrm{U}$ is beyond the scope of this paper.

The LIFS spectrum of the starting solid is shown in Fig. 3 and is similar to a LIFS spectrum of synthetic Na-boltwoodite given in Vochten et al. (1997). Vochten et al. list the positions of the three largest peaks at 508, 


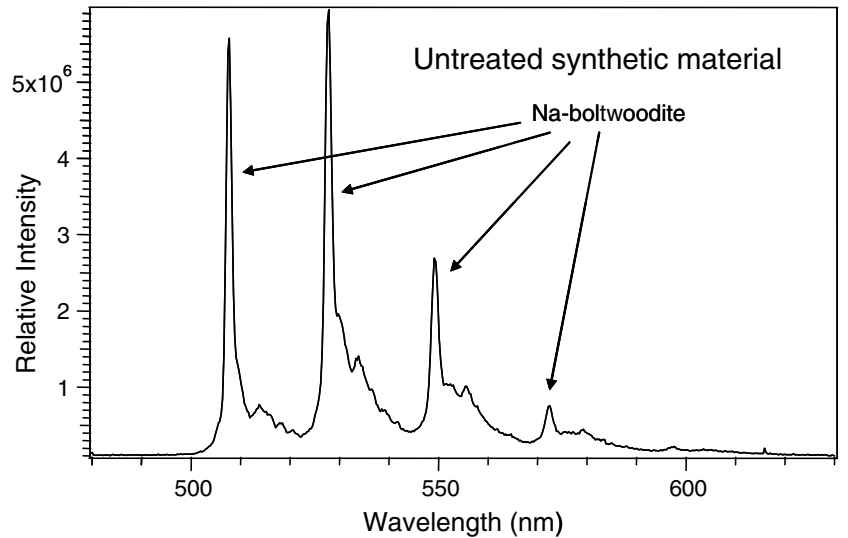

Fig. 3. The fluorescence spectrum of the synthetic material at liquid helium temperature and $415 \mathrm{~nm}$ excitation. The major peaks are arrowed and consistent with LIFS of synthetic Na-boltwoodite given in Vochten et al. (1997). The ultra-high energy resolution obtained at this low temperature has revealed previously undocumented features on the high wavenumber side of each major peak.

529 , and $551 \mathrm{~nm}$, which compares well with the three main peak positions determined in this study to be 507.6, 527.2, and $549.2 \mathrm{~nm}$ (arrowed in Fig. 3). Our spectrum displays sharper peaks than those in Vochten et al. (1997). This is likely due to the fact that our spectrum was obtained at $5.5 \pm 1.0 \mathrm{~K}$ compared to $77 \mathrm{~K}$ in Vochten et al. (1997). Further, the spectrum reveals additional structure on the high energy side of each major peak, which could have been obscured in previous work performed at higher temperatures. The solids from different synthetic batches also yielded very similar spectra, suggesting the synthesis process was reproducible.

\subsection{Dissolution experiments}

\subsubsection{Solution compositions}

Final $\mathrm{pH}$ values, and $\mathrm{U}(\mathrm{aq})$ and $\mathrm{Si}(\mathrm{aq})$ concentrations are given in Table 1 for all experiments. We note that variations in $\mathrm{pH}$ were less than $0.2 \mathrm{U}$ from $420 \mathrm{~min}$ to the end for all experiments. For pretreated experiments the variation in $\mathrm{pH}$ was less than 0.1 from start to finish. Fig. 4 shows the effect of carbonate/pH on the solubility of synthetic Na-boltwoodite after 7 days of reaction for the $0.25 \mathrm{~g} / 100 \mathrm{~mL}$ "equilibrium" experiments (not pretreated). Clearly, increasing carbonate/pH strongly enhanced the solubility of the synthetic material. Note that $\mathrm{Si}(\mathrm{a}-$ q) $>\mathrm{U}(\mathrm{aq})$ at bicarbonate values less than or equal to $0.6 \mathrm{mM}$, whereas $\mathrm{U}(\mathrm{aq})>\mathrm{Si}(\mathrm{aq})$ at bicarbonate concentrations greater than or equal to $1.2 \mathrm{mM}$. Note also that $\mathrm{Si}(\mathrm{aq})$ recorded a well-defined minimum around $0.6 \mathrm{mM}$ bicarbonate, but that $\mathrm{U}(\mathrm{aq})$ continued to drop with a minor recovery at 0 -added bicarbonate.

The time evolution of aqueous $\mathrm{Si}$ and $\mathrm{U}$ concentrations is shown in Fig. 5 for solutions containing 1.2, 6, and $50 \mathrm{mM}$ added bicarbonate and solid/solution ratio of $0.25 \mathrm{~g} / 100 \mathrm{~mL}$ (not pretreated). In all cases, initial rapid dissolution was followed by decreasing dissolution rates. After about 420 min of reaction, Si reached near steady state concentrations in the 1.2 and $6 \mathrm{mM}$ carbonate solutions (Fig. 5A and B). U(aq) appeared to reach steady state in the $6 \mathrm{mM} \mathrm{HCO}_{3}$ solution but not in the $1.2 \mathrm{mM} \mathrm{HCO}_{3}$ experiment. In contrast, both $\mathrm{Si}(\mathrm{aq})$ and $\mathrm{U}(\mathrm{aq})$ did not reach steady state in the $50 \mathrm{mM} \mathrm{HCO}_{3}$ solution (Fig. 5C). From $420 \mathrm{~min}$ to the end of experiment, $\mathrm{U}(\mathrm{aq})>\mathrm{Si}(\mathrm{aq})$ in both the 1.2 and $6 \mathrm{mM}$ bicarbonate solutions, but $\mathrm{U}(\mathrm{aq})$ was only marginally greater than

Table 1

Final solution compositions $\left(\mathrm{Na}^{\mathrm{a}}=50 \pm 1.1 \mathrm{mM} ; 23 \pm 2{ }^{\circ} \mathrm{C}\right)$

\begin{tabular}{|c|c|c|c|c|c|c|c|c|c|}
\hline \multirow[t]{2}{*}{$C_{\mathrm{T}}(\mathrm{mM})^{\mathrm{b}}$} & \multicolumn{3}{|c|}{ 7-Day exp. } & \multicolumn{3}{|c|}{ Kinetic exp. } & \multicolumn{3}{|c|}{ Pretreated exp. } \\
\hline & $\mathrm{pH}$ & $\mathrm{Si}(\mu \mathrm{M})$ & $\mathrm{U}(\mu \mathrm{M})$ & $\mathrm{pH}$ & $\mathrm{Si}(\mu \mathrm{M})$ & $\mathrm{U}(\mu \mathrm{M})$ & $\mathrm{pH}$ & $\mathrm{Si}(\mu \mathrm{M})$ & $\mathrm{U}(\mu \mathrm{M})$ \\
\hline 0.0 & 6.76 & 40.1 & 3.4 & & & & & & \\
\hline 0.3 & 7.46 & 12.6 & 4.3 & 7.54 & 11.4 & 1.8 & & & \\
\hline 0.6 & 7.80 & 8.0 & 5.8 & & & & & & \\
\hline 1.2 & 8.06 & 11.9 & 28.7 & 7.92 & 17.4 & 32.7 & 7.97 & 17.2 & 8.3 \\
\hline 3.5 & 8.51 & 36.8 & 93.7 & & & & & & \\
\hline 20.0 & 9.27 & 335.5 & 478.7 & & & & & & \\
\hline 30.0 & 9.47 & 500.0 & 573.5 & & & & & & \\
\hline 50.0 & 9.63 & 648.1 & 774.2 & 9.56 & 711.5 & 800.2 & 9.48 & 608.4 & 699.3 \\
\hline $50.0^{*}$ & & & & 9.55 & 912.4 & 1085.0 & & & \\
\hline $50.0^{* *}$ & & & & 9.67 & 923.5 & 1293.1 & & & \\
\hline $50.0^{* * *}$ & & & & 9.53 & 900.7 & 1332.3 & & & \\
\hline
\end{tabular}

All experiments were performed for 7 days with a $0.25 \mathrm{~g} / 100 \mathrm{ml}$ solid/solution ratio, unless noted otherwise: ${ }^{*} 0.5 \mathrm{~g} / 100 \mathrm{ml},{ }^{* *} 0.75 \mathrm{~g} / 100 \mathrm{ml},{ }^{* * *} 1 \mathrm{~g} / 100 \mathrm{ml}$. The 7-day experiments were only sampled once at 7 days of reaction, where the values given are the average of duplicate experiments. Only the 7-day data is given for the kinetic and pretreated experiments. Experiments called "pretreated", were leached with 50 mM bicarbonate solutions for 1 day. Detection limits for $\mathrm{U}(\mathrm{aq})$ and $\mathrm{Si}(\mathrm{aq})$ are 0.4 and $1.8 \mu \mathrm{M}$, respectively.

${ }^{a} \mathrm{Na}$ concentrations were held constant at $50 \mathrm{mM}$ with $\mathrm{NaHCO}_{3}$ and $\mathrm{NaNO}_{3}$.

${ }^{\text {b }} C_{\mathrm{T}}$ indicates the initial concentration of total carbon added as $\mathrm{NaHCO}_{3}$, but experiments were open to the atmosphere. 


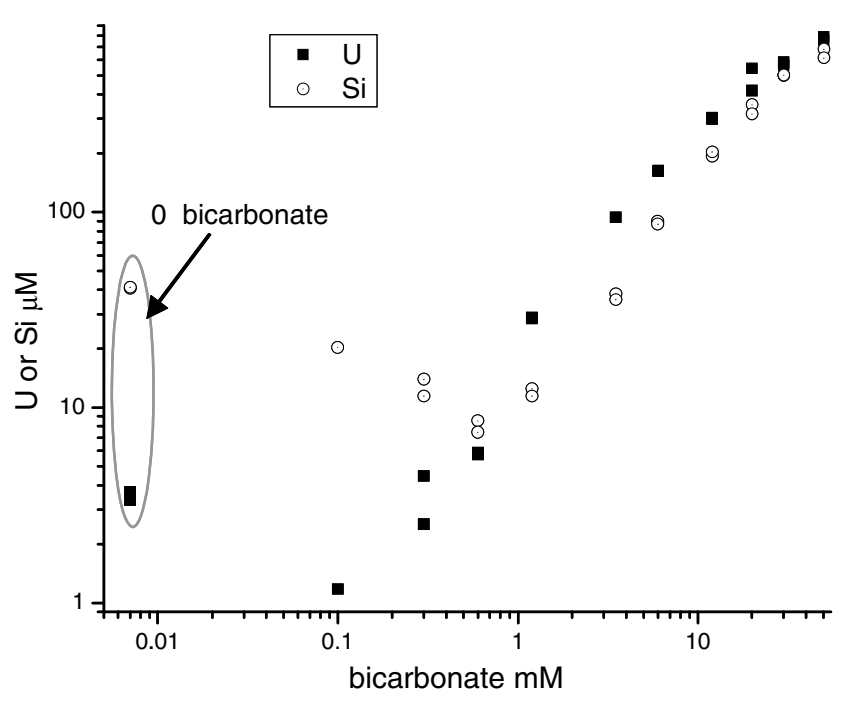

Fig. 4. Solubility plot of the synthetic material as a function of the initial bicarbonate concentration, added as $\mathrm{NaHCO}_{3}$. $\mathrm{pH}$ values ranged from 6.76 to 9.63 with increasing added bicarbonate. All experiments were in contact with air. $\mathrm{Na}(\mathrm{aq})$ held constant at $50 \pm 1.1 \mathrm{mM}$ by mixtures of $\mathrm{NaHCO}_{3}$ and $\mathrm{NaNO}_{3}$. Data is from the 7-day experiments (i.e., solutions sampled only once at the conclusion of each experiment. See Section 2.3). Both $\mathrm{U}(\mathrm{aq})$ and $\mathrm{Si}(\mathrm{aq})$ concentrations are plotted from duplicate experiments.

$\mathrm{Si}(\mathrm{aq})$ over the same time span in the $50 \mathrm{mM}$ bicarbonate experiment. At 0.1 and $0.3 \mathrm{mM}$ bicarbonate, $\mathrm{U}(\mathrm{aq})$ increased initially, then decreased abruptly and reached a plateau after about $420 \mathrm{~min}$ of reaction (Fig. 6). In contrast, $\mathrm{Si}(\mathrm{aq})$ increased, then plateaued and reached apparent steady state, where final $\mathrm{Si}(\mathrm{aq})$ concentrations were a factor of 10 greater than U(aq) concentrations (Fig. 6).

Fig. 7 illustrates the effect of increasing solid/solution ratios on dissolution. The time evolution of dissolution was similar for all four solid concentrations (see Fig. 5 for $0.25 \mathrm{~g} / 100 \mathrm{ml}$ experiments); one difference is that both $\mathrm{Si}(\mathrm{aq})$ and $\mathrm{U}(\mathrm{aq})$ approached steady state values after 10,000 min of dissolution only at higher solid concentrations (i.e., 0.75 and $1 \mathrm{~g}$ ). Interestingly, $\mathrm{Si}(\mathrm{aq})$ also reached steady state at $0.5 \mathrm{~g}$. It appears that any further increase in the solid/solution ratio would have negligible affect on $\mathrm{U}(\mathrm{aq})$ or $\mathrm{Si}(\mathrm{aq})$ concentrations.

We also pretreated the synthetic material in a $50 \mathrm{mM}$ bicarbonate solution for $24 \mathrm{~h}$, and then repeated the kinetic experiments for the $1.2,6$, and $50 \mathrm{mM}$ bicarbonate solutions (Fig. 8). Pretreatment changed the kinetic behavior of $\mathrm{U}(\mathrm{aq})$ in the 1.2 and $6 \mathrm{mM}$ bicarbonate experiments, whereas $\mathrm{Si}(\mathrm{aq})$ showed very similar behavior and final concentrations (Table 1). In both cases, U(aq) concentrations dropped relative to $\mathrm{Si}(\mathrm{aq})$, compared to the untreated experiments. At $1.2 \mathrm{mM}$ bicarbonate, $\mathrm{U}(\mathrm{aq}) / \mathrm{Si}(\mathrm{aq})$ ratios steadily decreased, which indicated precipitation of a U-rich, Si-poor phase, until both $\mathrm{U}(\mathrm{aq})$ and $\mathrm{Si}(\mathrm{aq})$ reached apparent steady state concentrations. At $6 \mathrm{mM}$ bicarbonate, U(aq) concentrations reached apparent steady state and were only marginally greater than $\mathrm{Si}(\mathrm{aq})$ concentra-
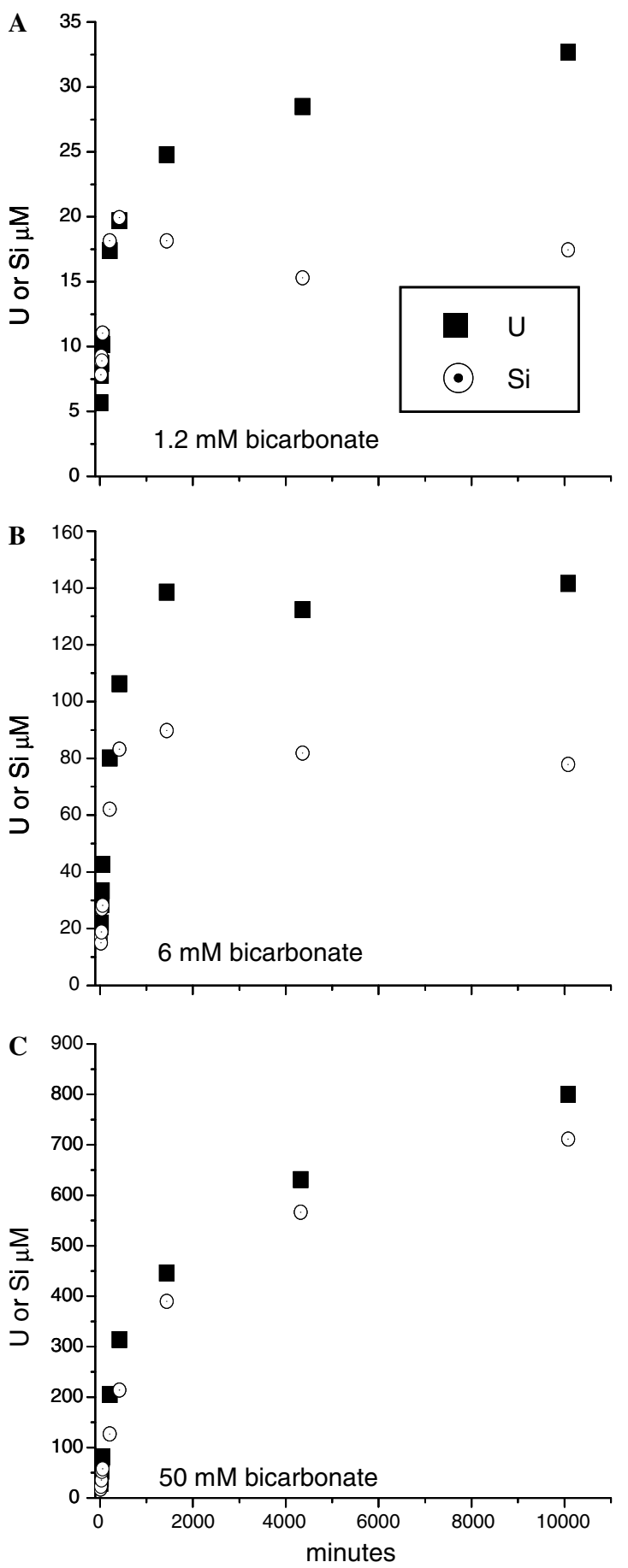

Fig. 5. Time evolution of $\mathrm{U}(\mathrm{aq})$ and $\mathrm{Si}(\mathrm{aq})$ concentrations for dissolution experiments using the untreated synthetic material $(0.25 \mathrm{~g} / 100 \mathrm{ml})$ at $(\mathrm{A})$ 1.2, (B) 6 , and (C) $50 \mathrm{mM}$ added bicarbonate.

tions. At $50 \mathrm{mM}$ bicarbonate, pretreatment simply lowered the final concentrations of $\mathrm{Si}(\mathrm{aq})$ and $\mathrm{U}(\mathrm{aq})$.

\subsubsection{Characterization of reacted solids}

XRD patterns of solids before and after reaction with $50 \mathrm{mM}$ bicarbonate indicated that all peaks with greater than $3.7 \%$ normalized intensity were present before and after dissolution. One minor peak apparently disappears in one spectrum after reaction, but this could be within the error 

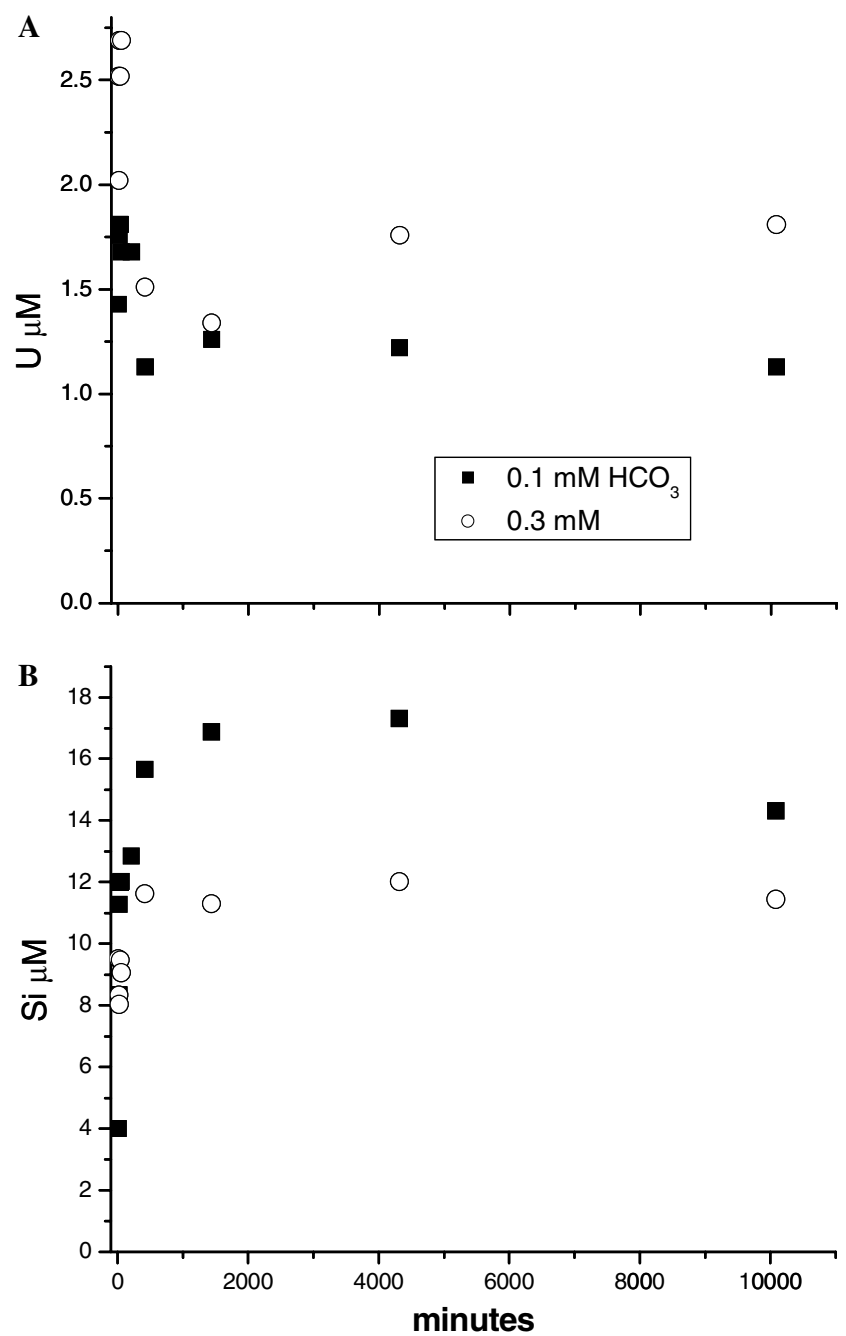

Fig. 6. Time evolution of (A) $\mathrm{U}(\mathrm{aq})$ and (B) Si(aq) concentrations for dissolution experiments using the untreated synthetic material $(0.25 \mathrm{~g} /$ $100 \mathrm{ml}$ ) at 0.1 and $0.3 \mathrm{mM}$ added bicarbonate.

of intensity shifts caused by variable orientation and hydration (see Section 2). No new peaks appeared after reaction.

For all reacted samples, XPS measurements indicate that the $\mathrm{BE}$ of the $\mathrm{U}_{4} \mathrm{f}_{7 / 2}$ line varied from 382.3 to 382.1 , which is within error of the $\mathrm{BE}$ for the starting material. The FWHM for the $\mathrm{U}_{4} \mathrm{f}_{7 / 2}$ and Si2s lines were strongly correlated and varied from 1.11 to 1.48 and 1.89 to 2.15 , respectively. Consequently, variations in FWHM were likely caused by Gaussian charge broadening. We note that a FWHM of 1.48 for $\mathrm{U}^{4} \mathrm{f}_{7 / 2}$ is narrow compared to literature values for monovalent $\mathrm{U}$ oxides/hydroxides and that a FWHM of 1.11 is perhaps unprecedented. Neither the shape (i.e., no asymmetry) nor the BEs of Si2p $(101.3 \pm 0.15 \mathrm{eV})$ and $\mathrm{Si} 2 \mathrm{~s}(152.8 \pm 0.1 \mathrm{eV})$ varied as a function of experimental conditions. The O1s spectra for all samples are very similar to the starting material. In sum, the peak parameters for $\mathrm{Si}, \mathrm{U}$, and $\mathrm{O}$ are not significantly different before and after reaction. U/Si ratios did not change significantly as a function of dissolution.

LIFS analyses (Fig. 9) showed that the primary peak positions and intensities of the untreated and reacted syn-
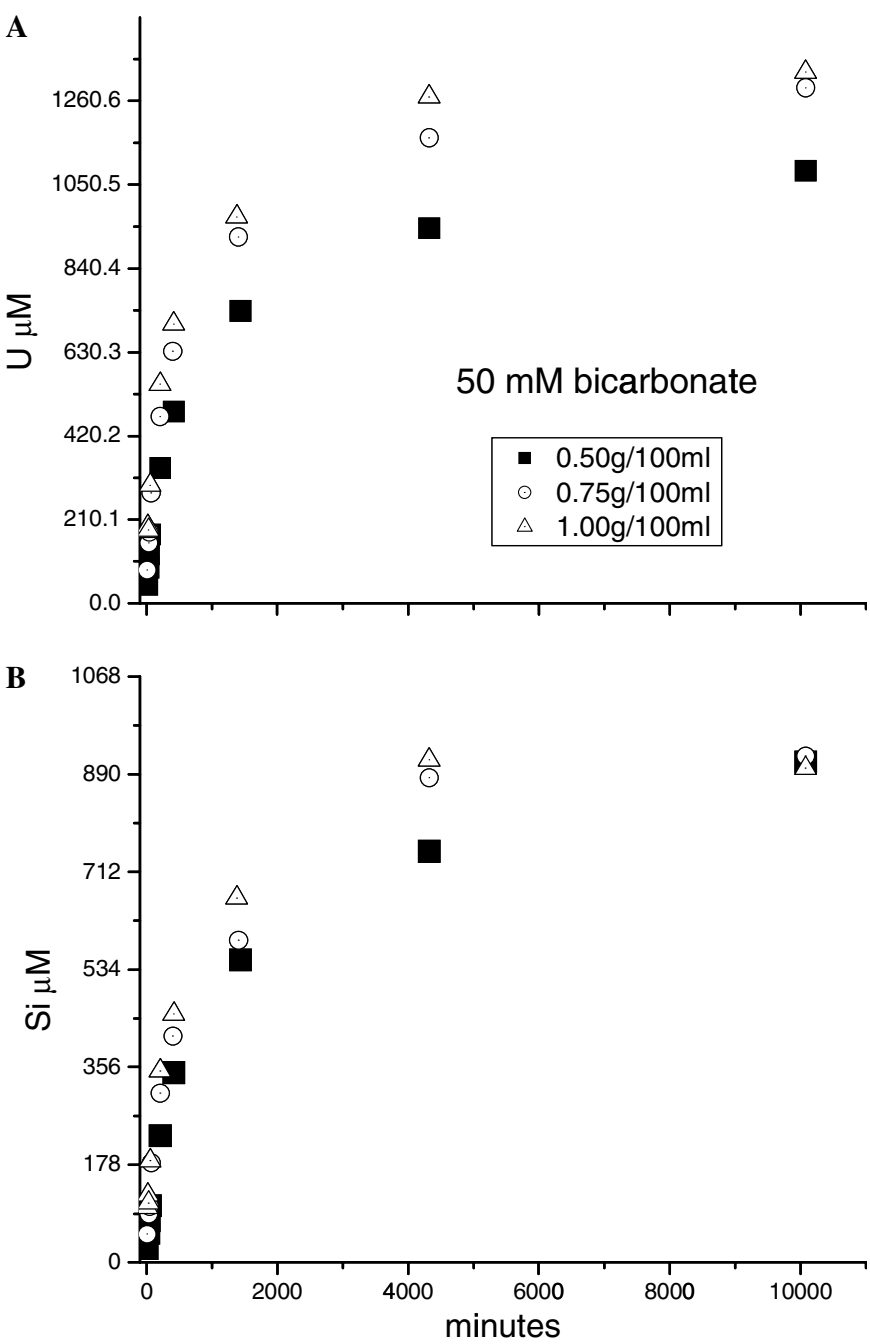

Fig. 7. Time evolution of (A) $\mathrm{U}(\mathrm{aq})$ and (B) $\mathrm{Si}(\mathrm{aq})$ concentrations for dissolution of untreated material at $50 \mathrm{mM}$ added bicarbonate. The dissolution is followed for three different solid/solution ratios: $0.50,0.75$, and $1.0 \mathrm{~g} / 100 \mathrm{ml}$.

thetic material are not significant functions of reaction time or bicarbonate concentration. However, there is a systematic broadening and increase in the intensity of the features on the high energy side of each main vibronic peak with increasing aqueous bicarbonate concentration. We have not been able to find any correspondence, including a search of the PNNL LIFS library of more than 20 uranyl species, between these secondary features and a known uranyl phase. It is possible that LIFS is recording a change in the crystallinity of the Na-boltwoodite or its near-surface that is accentuated with increasing aqueous bicarbonate concentration.

\section{Discussion}

\subsection{Dissolution stoichiometry}

Congruent dissolution of Na-boltwoodite should theoretically yield $\mathrm{U}(\mathrm{aq}) / \mathrm{Si}(\mathrm{aq})=1$. Clearly, our data does 

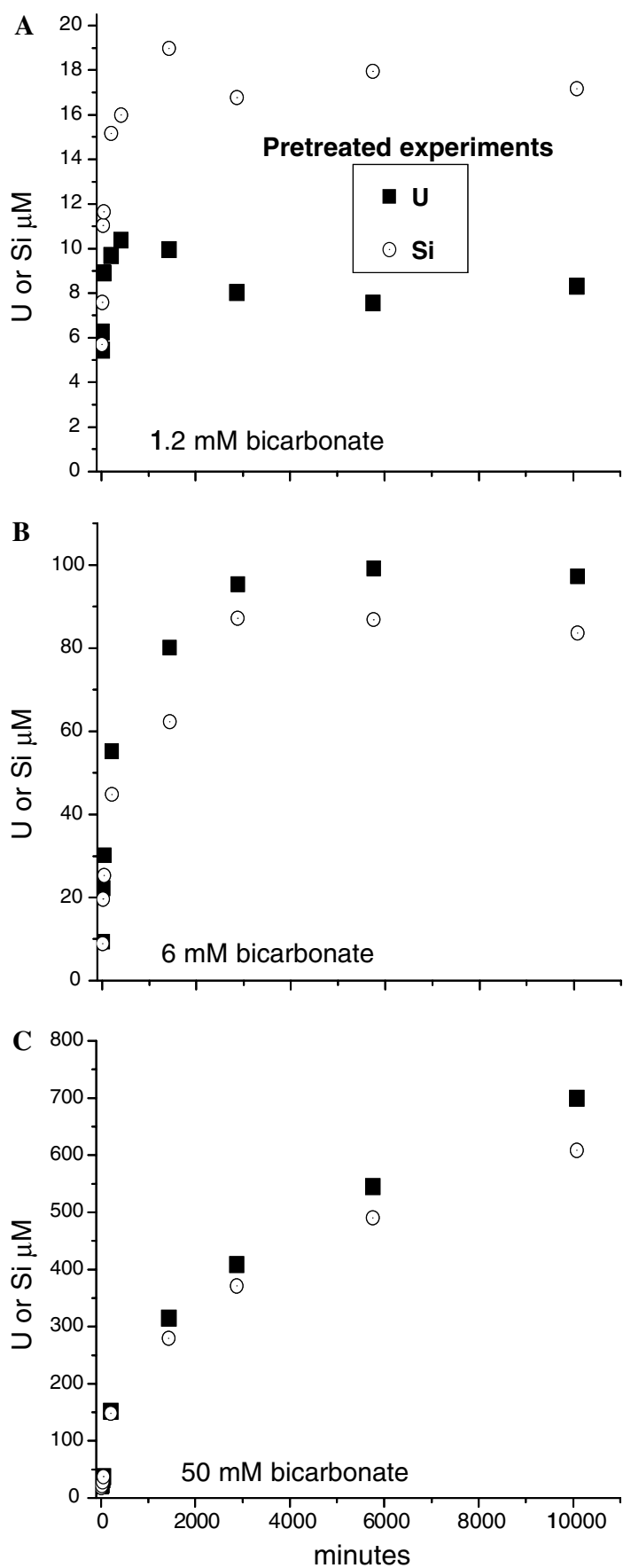

Fig. 8. Time evolution of $\mathrm{U}(\mathrm{aq})$ and $\mathrm{Si}(\mathrm{aq})$ concentrations for dissolution experiments using $0.25 \mathrm{~g}$ of the pretreated (leached in $50 \mathrm{mM}$ sodium bicarbonate solution for 1 day) synthetic material at (A) 1.2, (B) 6, and (C) $50 \mathrm{mM}$ added bicarbonate.

not record simple congruent behavior. For the untreated starting material, the time evolution data for 0.1 and $0.3 \mathrm{mM}$ bicarbonate solutions show that, after an initial period of rapid dissolution, $\mathrm{U}(\mathrm{aq})$ concentration dropped (Fig. 6A) whereas $\mathrm{Si}(\mathrm{aq})$ reached steady state (Fig. 6B). $\mathrm{U}(\mathrm{aq}) / \mathrm{Si}(\mathrm{aq})=0.35-0.15$ and $0.33-0.26$ up to about $180 \mathrm{~min}$ of reaction for the 0.1 and $0.3 \mathrm{mM}$ bicarbonate solutions, respectively, followed by a decrease to 0.07 and 0.14 . This is evidence that $\mathrm{U}(\mathrm{aq})$ became supersaturated

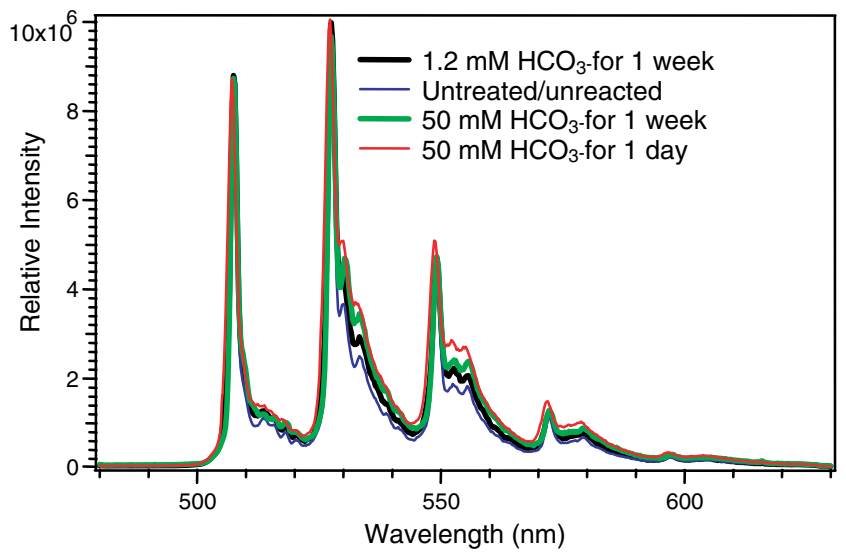

Fig. 9. LIFS spectra of unreacted and reacted synthetic material. Spectra were normalized to the height of the highest peak.

with respect to some U-rich, Si-poor phase which then precipitated. The lack of congruent dissolution before the sudden drop in $\mathrm{U}(\mathrm{aq})$ is likely an artifact of precipitation as well. We could not identify the precipitate as the amount is minuscule relative to the total material. At steady state, the calculated saturation index, $\log Q / K_{\mathrm{sp}}^{\mathrm{o}}$, for schoepite ranged from about -0.2 to -0.9 under these conditions. At 0 added bicarbonate $(\mathrm{pH}$ 6.76), the saturation index for soddyite was about -0.4 (using $K_{\mathrm{sp}}^{\mathrm{o}}$ from Nguyen et al., 1992) but near 0 using the recalculated value for $K_{\mathrm{sp}}^{\mathrm{o}}$ from Giammar and Hering (2002). Above $\mathrm{pH}$ 6.76, soddyite solubility rapidly increased. The clarkeite-like phase, $\mathrm{Na}_{2} \mathrm{U}_{2} \mathrm{O}_{7}$ was undersaturated for all conditions. The issue of what precipitated remains unresolved.

At higher bicarbonate concentrations the dissolution behavior of the untreated synthetic material is complicated, although there is no evidence for precipitation. These complications are highlighted in Fig. 10, where Si(aq) is plotted against $\mathrm{U}(\mathrm{aq})$. At $1.2 \mathrm{mM}$ bicarbonate, dissolution appears to be congruent up to 0.3 days. Subsequently, $\mathrm{Si}(\mathrm{aq})$ reached steady state (possibly a slight downward trend), whereas $\mathrm{U}(\mathrm{aq})$ continued to increase (Fig. 10A). At $6 \mathrm{mM}$ bicarbonate, dissolution appears to be consistently incongruent with $\mathrm{U}(\mathrm{aq}) / \mathrm{Si}(\mathrm{aq})>1$ (Fig. 10B). After 0.3 days, $\mathrm{Si}(\mathrm{aq})$ reached a plateau but $\mathrm{U}(\mathrm{aq})$ increased up until 1 day and then reached steady state. At $50 \mathrm{mM}$ bicarbonate, dissolution appears incongruent initially, but then approaches congruency where $\mathrm{U}(\mathrm{aq}) / \mathrm{Si}(\mathrm{aq})=1.1$ after 1 day of reaction (Fig. 10C). However, at higher solid/solution ratios and at $50 \mathrm{mM}$ bicarbonate, dissolution does not approach congruency (Fig. 10D) and, after 3 days of reaction, $\mathrm{Si}(\mathrm{aq})$ reached steady state and $\mathrm{U}(\mathrm{aq})$ increased only marginally.

The question is whether incongruent dissolution occurred, which to the best of our knowledge has not been previously documented for uranyl silicates. Perez et al. (1997) stated that uranophane dissolves congruently in bicarbonate solutions, but only performed spot checks on $\mathrm{U}(\mathrm{aq}) / \mathrm{Si}(\mathrm{aq})$ ratios (data not shown). Giammar and Hering (2002) provided evidence for congruent dissolution 

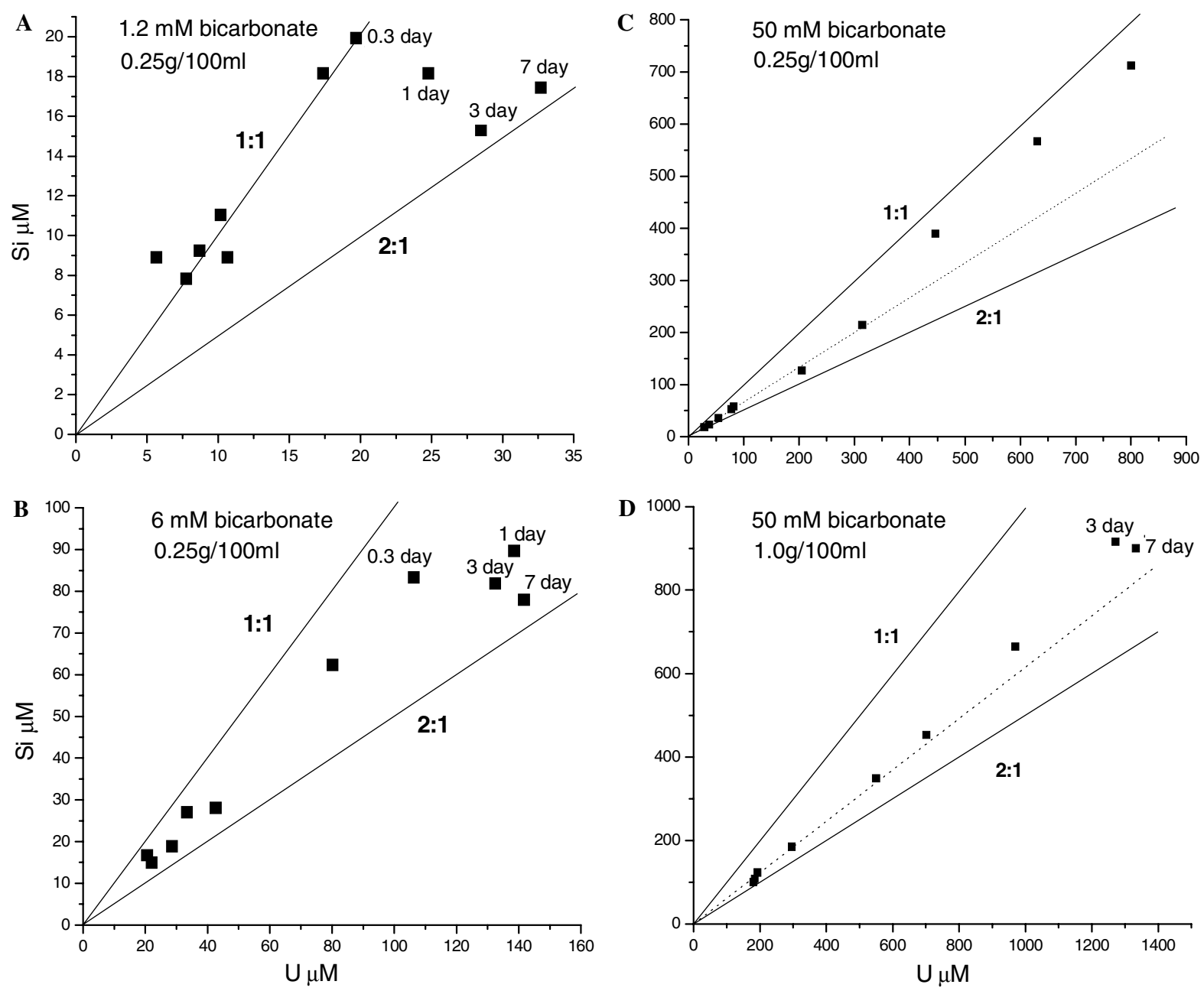

Fig. 10. Si(aq) plotted against $\mathrm{U}(\mathrm{aq})$ to illustrate apparent incongruent or congruent dissolution. Experiments performed with untreated starting material $(0.25 \mathrm{~g} / 100 \mathrm{ml})$ at (A) 1.2 , (B) 6 , and (C) $50 \mathrm{mM}$ added bicarbonate. Panel (D) show results for the highest solid/solution ratio (1 g/100 ml) and at $50 \mathrm{mM}$ added bicarbonate.

of soddyite at $\mathrm{pH}=6$ and no carbonate. However, there is evidence for incongruent dissolution of other silicates containing non polymerized $\mathrm{SiO}_{4}$ tetrahedra, such as olivine (Pokrovsky and Schott, 2000a,b). In particular, these studies have shown that olivine exhibits an initial period of incongruent dissolution, where either $\mathrm{Si}$ or $\mathrm{Mg}$ is preferentially leached depending on $\mathrm{pH}$, followed by congruent dissolution. This is similar to the observed dissolution behavior of Na-boltwoodite in the $50 \mathrm{mM}$ bicarbonate and $0.25 \mathrm{~g} / 100 \mathrm{~mL}$ experiments, where an initial period of apparent preferential leaching of uranyl was followed by a close approach to congruent dissolution (Fig. 10C). However, at all other conditions an initial period of either apparent congruent (1.2 $\mathrm{mM}$ bicarbonate) or apparent incongruent $(6 \mathrm{mM}$ bicarbonate and $50 \mathrm{mM}$ bicarbonate $[1 \mathrm{~g} / 100 \mathrm{~mL}])$ dissolution was followed by $\mathrm{Si}(\mathrm{aq})$ reaching near steady state concentrations but continued increases in $\mathrm{U}(\mathrm{aq})$.

It is difficult to fit all of these observations into a coherent and self consistent description of Na-boltwoodite dissolution. The one common denominator for most of the experiments, at or above $1.2 \mathrm{mM}$ bicarbonate, that used untreated starting material is that $\mathrm{Si}(\mathrm{aq})$ reached steady state, but $\mathrm{U}(\mathrm{aq})$ continued to increase (albeit at a slower rate or only marginally). Given that there is no evidence for $\mathrm{Si}$ precipitation and $\mathrm{Si}(\mathrm{aq})$ concentrations are well below saturation of amorphous $\mathrm{SiO}_{2}$ in all the experiments, it is likely that steady state $\mathrm{Si}(\mathrm{aq})$ concentrations mark a cessation to Na-boltwoodite dissolution. Any further increase in $\mathrm{U}(\mathrm{aq})$ concentrations would then indicate continued dissolution of a uranyl-rich, silica-deficient phase, possibly minor and hence undetected amounts of a uranyl oxy(hydroxide). This would be consistent with thermodynamic calculations which indicate that schoepite, for example, is more soluble than Na-boltwoodite at all experimental conditions. As discussed by Giammar and Hering (2002), small concentrations of a contaminant can influence $\mathrm{U}(\mathrm{aq})$ concentrations. For example, mass balance calculations indicate that a $\sim 1-2 \mathrm{~mole} \%$ impurity of schoepite could provide the excess $\mathrm{U}(\mathrm{aq})$ in all the experiments at $\geqslant 1.2 \mathrm{mM}$ bicarbonate, assuming congruent dissolution of Na-boltwoodite. Conventional powder XRD is not 
sensitive enough to monitor such small concentrations. Likewise, LIFS did not record the loss of any peak after reaction (Section 3.2.1). The fact that we could not find a contaminant with TEM is possibly explained by its low concentration and perhaps by being hidden in some of the dense mats formed by the Na-boltwoodite needles/ blades (Fig. 1). Consequently, there is no direct evidence for a contaminant.

The near-surface U/Si ratios, as measured by XPS, of reacted materials are not significantly different than for the unreacted material. This is consistent with the chemical state of $\mathrm{Si}$; $\mathrm{Si} 2 \mathrm{p}$ BEs of reacted and unreacted boltwoodite all cluster very closely around $101.2 \mathrm{eV}$, which indicates that XPS did not detect $\mathrm{SiO}_{4}$ polymerization (see Sections 3.1 and 3.2.2). Likewise, $\mathrm{O} / \mathrm{Si}$ ratios are not significantly different between the starting and reacted material. Consequently, XPS analyses are consistent with congruent dissolution.

Pretreatment of the starting material with $50 \mathrm{mM}$ bicarbonate solution strongly affected dissolution (compare Figs. 8 and 5), where U(aq) concentrations were lowered using pretreated compared to untreated material. In fact pretreatment appeared to uncover a $\mathrm{U}(\mathrm{aq})$ precipitation event in the $1.2 \mathrm{mM}$ bicarbonate solution (again, the precipitate was not recorded by any of our solid state analytical methods). Perez et al. (1997), gave significantly higher concentrations of $\mathrm{U}(\mathrm{aq})$ for similar conditions during dissolution of uranophane. We postulate that the presence of $\mathrm{Ca}$ formed a Ca-uranyl-carbonate complex that enhanced the solubility of $\mathrm{U}(\mathrm{VI})$ in their experiments and prevented precipitation.

Further, in contrast to using untreated material, pretreatment yielded steady state conditions for $\mathrm{U}(\mathrm{aq})$ at 1.2 and $6 \mathrm{mM}$ bicarbonate concentrations and near congruent dissolution behavior over the entire reaction period for the 6 and $50 \mathrm{mM}$ bicarbonate experiments (Fig. 11). This behavior is consistent with pretreatment preferentially dissolving a minor U-rich, Si-deficient contaminant, creating a purified Na-boltwoodite starting material. If this is so, then these experiments provide evidence that $\mathrm{Na}$-boltwoodite is dissolving in a near congruent manner, in accord with XPS analyses.

\subsection{Equilibrium}

Importantly, both $\mathrm{U}(\mathrm{aq})$ and $\mathrm{Si}(\mathrm{aq})$ reached steady state in many of the experiments and Na-boltwoodite was the only identifiable phase at all conditions. Consequently, in what follows, we calculated solubility product constants from experiments that used both untreated and pretreated starting materials, where the only criterion was attainment of steady state for $\mathrm{pH}, \mathrm{U}(\mathrm{aq})$, and $\mathrm{Si}(\mathrm{aq})$. The solubility product constant, $K_{\mathrm{sp}}^{\mathrm{o}}=\left\{\mathrm{H}_{2} \mathrm{O}\right\}^{1.5}\left\{\mathrm{H}_{4} \mathrm{SiO}_{4}\right\}\left\{\mathrm{Na}^{+}\right\}\left\{\mathrm{UO}_{2}{ }^{2+}\right\} /\left\{\mathrm{H}^{+}\right\}^{3}$, was calculated at different conditions for the reaction

$$
\begin{aligned}
& \mathrm{Na}\left[\mathrm{UO}_{2}\left(\mathrm{SiO}_{3} \mathrm{OH}\right)\right]\left(\mathrm{H}_{2} \mathrm{O}\right)_{1.5}+3 \mathrm{H}^{+} \\
& \quad=\mathrm{UO}_{2}{ }^{2+}+\mathrm{Na}^{+}+\mathrm{H}_{4} \mathrm{SiO}_{4}+1.5 \mathrm{H}_{2} \mathrm{O}
\end{aligned}
$$
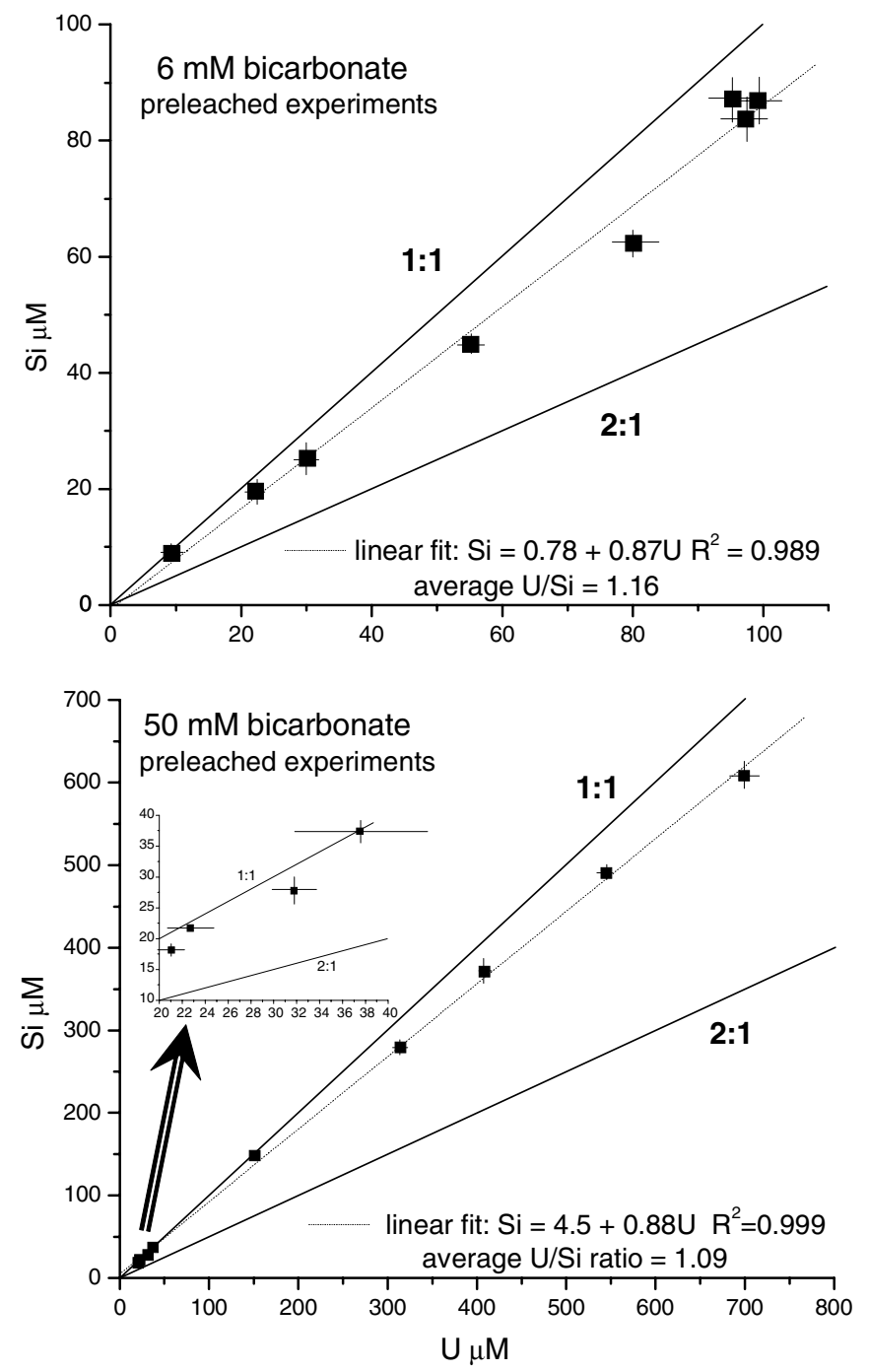

Fig. 11. Si(aq) plotted against $\mathrm{U}(\mathrm{aq})$ to illustrate apparent incongruent or congruent reaction. The error is given as $1 \sigma$ of the analytical uncertainty. Experiments performed with pretreated starting material $(0.25 \mathrm{~g} / 100 \mathrm{ml})$ at 6 (top panel) and $50 \mathrm{mM}$ (bottom panel) added bicarbonate.

Because carbonate and mixed carbonate-hydroxyl uranyl species dominated under the experimental conditions, we needed to consider all relevant complexation reactions in order to calculate reaction (1) $K_{\mathrm{sp}}^{\mathrm{o}}$; the reactions and their associated stability constants are listed in Table 2. Given that ionic strength was moderate (0.05-0.06), we used the Davies equation (Davies, 1962) to calculate activity coefficients for all species. However, we also used the ion-interaction model of Pitzer and coworkers (Pitzer, 1973, 1991), with Pitzer parameters recently calibrated by Felmy et al. (2005), to account for ionic strength effects. In particular, we were curious if the highly charged uranyl-tricarbonato species, which dominates at higher $\mathrm{pH}$ and carbonate concentrations (e.g., the U-tricarbonato species accounts for $>98 \% \mathrm{U}(\mathrm{aq})$, at $\mathrm{pH} 8.67$ and $\mathrm{C}_{\mathrm{T}}=3 \mathrm{mM}$ ), required special treatment. Initial nitrate(aq) and $\mathrm{Na}(\mathrm{aq})$, and measured $\mathrm{U}(\mathrm{aq}), \mathrm{Si}(\mathrm{aq})$, and $\mathrm{pH}$ (average of steady state values) were fixed input for the calculations. We note that $\mathrm{Na}$ was introduced at $50 \mathrm{mM}$ as 
Table 2

Equilibrium speciation reactions used to derive $\log K_{\mathrm{sp}}^{\mathrm{o}}$

\begin{tabular}{|c|c|c|}
\hline Speciation reaction & $\log K(\mathrm{I}=0)$ & Source \\
\hline $\mathrm{UO}_{2}^{2+}+\mathrm{H}_{2} \mathrm{O}=\mathrm{UO}_{2} \mathrm{OH}^{+}+\mathrm{H}^{+}$ & -5.25 & 1 \\
\hline $\mathrm{UO}_{2}^{2+}+2 \mathrm{H}_{2} \mathrm{O}=\mathrm{UO}_{2}(\mathrm{OH})_{2}(\mathrm{aq})+2 \mathrm{H}^{+}$ & -12.15 & 1 \\
\hline $\mathrm{UO}_{2}^{2+}+3 \mathrm{H}_{2} \mathrm{O}=\mathrm{UO}_{2}(\mathrm{OH})_{3}^{-}+3 \mathrm{H}^{+}$ & -20.25 & 1 \\
\hline $2 \mathrm{UO}_{2}^{2+}+\mathrm{H}_{2} \mathrm{O}=\left(\mathrm{UO}_{2}\right)_{2} \mathrm{OH}^{3+}+\mathrm{H}^{+}$ & -2.70 & 1 \\
\hline $2 \mathrm{UO}_{2}{ }^{2+}+2 \mathrm{H}_{2} \mathrm{O}=\left(\mathrm{UO}_{2}\right)_{2}(\mathrm{OH})_{2}{ }^{2+}+2 \mathrm{H}^{+}$ & -5.62 & 1 \\
\hline $3 \mathrm{UO}_{2}{ }^{2+}+4 \mathrm{H}_{2} \mathrm{O}=\left(\mathrm{UO}_{2}\right)_{3}(\mathrm{OH})_{4}{ }^{2+}+4 \mathrm{H}^{+}$ & -11.90 & 1 \\
\hline $4 \mathrm{UO}_{2}^{2+}+7 \mathrm{H}_{2} \mathrm{O}=\left(\mathrm{UO}_{2}\right)_{4}(\mathrm{OH})_{7}^{+}+7 \mathrm{H}^{+}$ & -21.90 & 1 \\
\hline $\mathrm{UO}_{2}^{2+}+\mathrm{CO}_{3}^{2-}=\mathrm{UO}_{2} \mathrm{CO}_{3}(\mathrm{aq})$ & 9.94 & 1 \\
\hline $\mathrm{UO}_{2}^{2+}+2 \mathrm{CO}_{3}^{2-}=\mathrm{UO}_{2}\left(\mathrm{CO}_{3}\right)_{2}^{2-}$ & 16.61 & 1 \\
\hline $\mathrm{UO}_{2}^{2+}+3 \mathrm{CO}_{3}^{2-}=\mathrm{UO}_{2}\left(\mathrm{CO}_{3}\right)_{3}^{4-}$ & 21.84 & 1 \\
\hline $3 \mathrm{UO}_{2}^{2+}+6 \mathrm{CO}_{3}^{2-}=\left(\mathrm{UO}_{2}\right)_{3}\left(\mathrm{CO}_{3}\right)_{6}{ }^{6-}$ & 54.00 & 1 \\
\hline $2 \mathrm{UO}_{2}^{2+}+\mathrm{CO}_{3}^{2-}+3 \mathrm{H}_{2} \mathrm{O}=\left(\mathrm{UO}_{2}\right)_{2} \mathrm{CO}_{3}^{-}(\mathrm{OH})^{3-}+3 \mathrm{H}^{+}$ & -0.86 & 1 \\
\hline $\mathrm{CO}_{2}(\mathrm{~g})+\mathrm{H}_{2} \mathrm{O}=\mathrm{H}_{2} \mathrm{CO}_{3}$ & -1.47 & 1 \\
\hline $\mathrm{H}_{2} \mathrm{CO}_{3}=\mathrm{H}^{+}+\mathrm{HCO}_{3}^{-}$ & -6.35 & 1 \\
\hline $\mathrm{H}_{2} \mathrm{CO}_{3}=2 \mathrm{H}^{+}+\mathrm{CO}_{3}^{2-}$ & -16.68 & 1 \\
\hline $\mathrm{H}_{4} \mathrm{SiO}_{4}=2 \mathrm{H}^{+}+\mathrm{H}_{2} \mathrm{SiO}_{4}{ }^{2-}$ & -23.14 & 1 \\
\hline $\mathrm{H}_{4} \mathrm{SiO}_{4}=\mathrm{H}^{+}+\mathrm{H}_{3} \mathrm{SiO}_{4}^{-}$ & -9.81 & 1 \\
\hline $\mathrm{Na}^{+}+\mathrm{CO}_{3}^{2-}=\mathrm{NaCO}_{3}^{-}$ & -1.27 & 2 \\
\hline $\mathrm{Na}^{+}+\mathrm{CO}_{3}^{2-}+\mathrm{H}^{+}=\mathrm{NaHCO}_{3}(\mathrm{aq})$ & -10.03 & 2 \\
\hline
\end{tabular}

${ }^{1}$ Guillaumont et al. (2003); ${ }^{2}$ NIST (2001).

some combination of $\mathrm{NaNO}_{3}$ and $\mathrm{NaHCO}_{3}$, and that any increase in $\mathrm{Na}(\mathrm{aq})$ due to Na-boltwoodite dissolution would have been well within analytical error. The model solution, with an initial concentration of added bicarbonate, was then equilibrated with atmospheric $\mathrm{P}_{\mathrm{CO}_{2}}$.

Calculated $K_{\mathrm{sp}}^{\mathrm{o}}$ values are given in Table 3 for 10 experiments that clearly manifested steady state. We made two exceptions. Experiments using untreated starting material at $0.5,0.75$, and $1 \mathrm{~g} / 100 \mathrm{ml}$ reached nearly identical steady state concentrations for $\mathrm{Si}(\mathrm{aq})$. In contrast, despite near convergence of $\mathrm{U}(\mathrm{aq})$ concentrations for the 0.75 and $1 \mathrm{~g} / 100 \mathrm{ml}$ experiments, it is possible that $\mathrm{U}(\mathrm{aq})$ did not quite reach steady state. Consequently, we used an average of the $\mathrm{Si}(\mathrm{aq})$ steady state concentrations from the untreated $0.5,0.75$, and $1 \mathrm{~g} / 100 \mathrm{ml}$ experiments together with the 7 th day, or highest, $\mathrm{U}(\mathrm{aq})$ concentration from the $1 \mathrm{~g} / 100 \mathrm{ml}$ experiment to calculate a minimum solubility constant for Na-boltwoodite. Although $\mathrm{U}(\mathrm{aq})$ has not necessarily reached steady state, we note that $\mathrm{U}(\mathrm{aq})$ values are beginning to converge for the different solid/solution ratios (Fig. 7A) and that changes in $\mathrm{U}(\mathrm{aq})$ are marginal from 4300 to 10,080 minutes (end experiment; see Fig. 7B). We also included $\log K_{\mathrm{sp}}^{\mathrm{o}}$ calculated from the 0 added bicarbonate 7-day experiments, because the kinetic data suggested that steady state tended to be achieved rapidly at less than $1.2 \mathrm{mM}$ bicarbonate.

The $\log K_{\mathrm{sp}}^{\mathrm{o}}$ values are consistent over a wide range of solution compositions, experimental design, apparent precipitation or not, and the use of untreated and pretreated starting material. The average $\log K_{\mathrm{sp}}^{\mathrm{o}}$ for all 10 determi- nations is $5.86 \pm 0.24(1 \sigma)$ or $5.85 \pm 0.0 .26(1 \sigma)$; using the Pitzer ion-interaction model or Davies equation, respectively. Clearly, and as expected, the moderate ionic strength of these experiments does not distinguish between the Pitzer ion-interaction model and the Davies equation from 0 to $6 \mathrm{mM}$ added bicarbonate. A difference may be manifest at $50 \mathrm{mM}$ bicarbonate, but more data is required to evaluate this possibility. $\log K_{\mathrm{sp}}^{\mathrm{o}}$ values are marginally higher for the two experiments that used pretreated material. More data is needed to evaluate the significance of this difference. Finally, the results are consistent with $\log K_{\mathrm{sp}}^{\mathrm{o}}=5.82$ determined by Nguyen et al. (1992), at $\mathrm{pH} 4.5$ and under Ar.

\subsection{Controls on solubility and dissolution kinetics}

We limited evaluating controls on solubility and dissolution kinetics to the pretreated experiments in order to minimize convoluting contributions from Na-boltwoodite with the hypothesized minor U-rich, Si-deficient contaminant. Further, in contrast to the untreated starting material, $\mathrm{pH}$ was nearly constant from start to finish for experiments that used the pretreated material. Fig. 12 shows $\mathrm{Si}(\mathrm{aq})$ versus time for just the first 210 min of reaction at 1.2, 6, and $50 \mathrm{mM}$ added bicarbonate. $\mathrm{Si}(\mathrm{aq})$ is a better proxy for $\mathrm{Na}-$ boltwoodite dissolution than $\mathrm{U}(\mathrm{aq})$ because $\mathrm{U}(\mathrm{aq})$ appears to eventually precipitate at $1.2 \mathrm{mM}$ added bicarbonate. Dissolution rates (Fig. 12), as well as solubility (Fig. 8), increased with increasing bicarbonate and $\mathrm{pH}$. With respect to solubility, calculations indicate that the dominant uranyl 


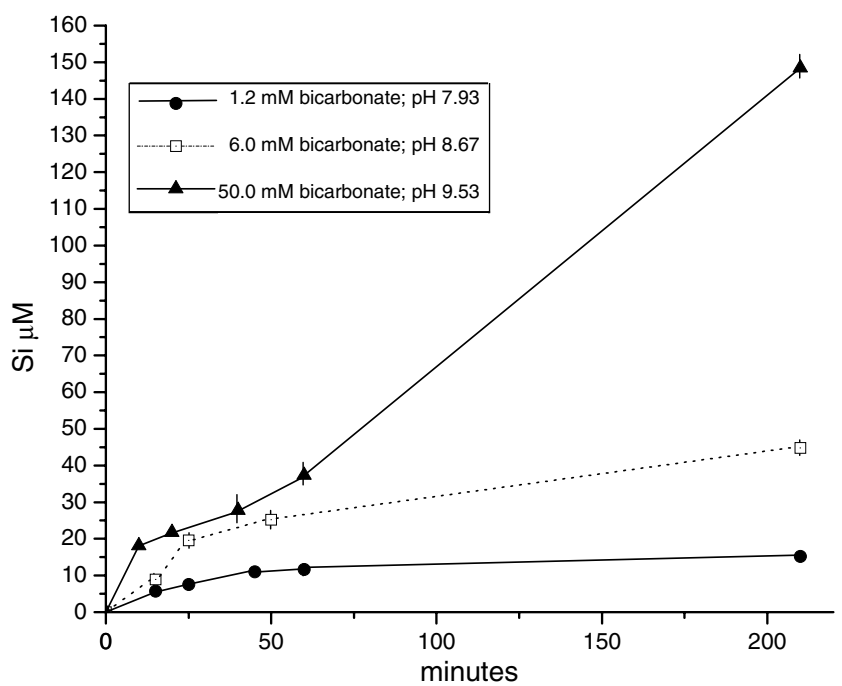

Fig. 12. Comparison of far from equilibrium dissolution kinetics for pretreated synthetic material at $1.2,6$, and $50 \mathrm{mM}$ added bicarbonate. $\mathrm{Na}$ (aq) was fixed at $0.050+1.1 \mathrm{mM}$. Solid/solution ratios were $0.25 \mathrm{~g} /$ $100 \mathrm{ml}$. The difference in the initial and final $\mathrm{pH}$ for each experiment was $\leqslant 0.1$. The error is given as $1 \sigma$ of the analytical uncertainty.

species shifts from the mixed carbonate-hydroxy complex to the tricarbonato complex between 1.2 and $6 \mathrm{mM}$ added bicarbonate (Table 4), where the corresponding $\mathrm{pH}$ increases from 7.93 to 8.67 . Importantly, silicic acid speciation is almost insensitive to $\mathrm{pH}$ over this range, and it appears likely that uranyl complexation with carbonate ions is driving the increase in solubility of Na-boltwoodite. In contrast, silicic acid significantly dissociates to $\mathrm{H}_{3} \mathrm{SiO}_{4}{ }^{-}$ with $\mathrm{pH}$ above $\mathrm{pH} \sim 9$. Consequently, it is likely that both uranyl complexation with carbonate ions and silicic acid dissociation drive the increased solubility of Na-boltwoodite from $\mathrm{pH} 8.67$ (6 $\mathrm{mM}$ added bicarbonate) to $\mathrm{pH} 9.53$ (50 $\mathrm{mM}$ added bicarbonate).

A previous study (Steward and Mones, 1997) indicated that carbonate has a much stronger control on uranium (hydr)oxide dissolution rates than $\mathrm{pH}$ in the alkaline regime ( $\mathrm{pH} \mathrm{8-10).} \mathrm{It} \mathrm{follows} \mathrm{that} \mathrm{increasing} \mathrm{carbonate}$ should contribute to increasing the dissolution rates of Na-boltwoodite from pH 7.93 to 9.53. However, Na-boltwoodite is a one to one solid solution of $\mathrm{U}$ and $\mathrm{Si}$, and it is well-known that $\mathrm{SiO}_{2}$ (quartz and amorphous silica) and aluminosilicate dissolution rates increase as a function of $\mathrm{pH}$ above $\mathrm{pH} \sim 6$ due to the deprotonation of $>\mathrm{SiOH}^{\circ}$ surface species. Consequently, both carbonate and $\mathrm{pH}$

Table 4

Proportion of $\mathrm{U}(\mathrm{aq})$ in dominant uranyl complexes

\begin{tabular}{rlllll}
\hline$C_{\mathrm{T}}$ & $\mathrm{pH}$ & $\mathrm{UO}_{2}\left(\mathrm{CO}_{3}\right)_{3}{ }^{4-}$ & $\left(\mathrm{UO}_{2}\right)_{2} \mathrm{CO}_{3} \mathrm{OH}_{3}{ }^{-}$ & $\mathrm{UO}_{2}\left(\mathrm{CO}_{3}\right)_{2}{ }^{2-}$ & $\mathrm{UO}_{2} \mathrm{CO}_{3}$ \\
\hline 1.2 & 7.93 & 0.306 & 0.577 & 0.105 & 0.006 \\
6.0 & 8.67 & 0.988 & - & 0.011 & - \\
50.0 & 9.53 & 0.9998 & - & - & - \\
\hline
\end{tabular}

$C_{\mathrm{T}}$ is the initial total carbon added as $\mathrm{NaHCO}_{3}$. Experiments were open to air. 
related surface reactions could account for increases in the Na-boltwoodite dissolution rate. Without additional experiments, we cannot distinguish the importance of these two mechanisms.

\section{Conclusions}

The solubility of synthetic Na-boltwoodite was determined from $\mathrm{pH} \sim 6.8-\sim 9.5$ and over a wide range of bicarbonate concentrations. Aqueous uranyl carbonate complexes strongly enhanced $\mathrm{Na}$-boltwoodite solubility from $\mathrm{pH} 7.9$ to 9.5. $\mathrm{pH}$ driven dissociation of silicic acid could also have contributed to the measured solubility at $\mathrm{pH}>\sim 9$. From $\mathrm{pH} 7.9$ to 9.5 , dissolution rates increased with increasing carbonate concentration and $\mathrm{pH}$. It is possible that both carbonate (effect on $\mathrm{U}$ ) and $\mathrm{pH}$ (effect on $\mathrm{Si}$ ) related surface reactions controlled the dissolution kinetics. However, the experiments were not designed to distinguish the relative importance of these mechanisms. Dissolution was determined to be near congruent. LIFS recorded systematic broadening and increases in intensity of secondary features on the high energy side of the main vibronic peaks of Na-boltwoodite with increasing bicarbonate concentrations in the experimental solutions. This is a new observation, made possible by working with cryogenic LIFS at near liquid $\mathrm{He}$ temperature. Our working hypothesis is that these evolving features record changes in the crystallinity of the near-surface of the Na-boltwoodite.

Derived solubility product constants were consistent across a broad range of solution compositions and yielded an average $K_{\mathrm{sp}}^{\mathrm{o}}$ nearly identical to the $K_{\mathrm{sp}}^{\mathrm{o}}$ determined by Nguyen et al. (1992) under different conditions ( $\mathrm{pH}=4.5$, $\mathrm{Ar}$ atmosphere). The results confirm that the attainment of steady state conditions and the continued presence of Na-boltwoodite were sufficient criteria to establish a consistent set of values for $K_{\mathrm{sp}}^{\mathrm{o}}$. The use of the Davies equation or the Pitzer ion-interaction model to correct for ionic strength effects gave nearly identical results up to $6 \mathrm{mM}$ added bicarbonate.

Uranium solubility experiments, including our own, can be plagued by the presence of contaminants or secondary precipitates. The myriad of possible uranyl minerals makes solubility studies of uranium phases particularly difficult. As noted by Perez et al. (2000), working at high carbonate concentrations has the advantage of limiting precipitation of secondary phases. Here we have shown that a combination of solid state characterization methods, pretreatment, and varying solid/solution ratios can provide valuable constraints on data interpretation.

\section{Acknowledgments}

We thank David E. McCready for XRD and Chongmin Wang for TEM analyses. We also appreciate the comments of two anonymous reviewers, Jordi Bruno, and Jacques Schott that greatly improved the quality of the manuscript.
The research was supported by the U.S. Department of Energy (DOE) through the Natural and Accelerated Biological Remediation (NABIR) program. A portion of this research was performed in the Environmental Molecular Science Laboratory (user proposal \#4691), a national user facility run by Battelle for the U.S. DOE. Pacific Northwest National Laboratory is operated for the DOE by Battelle Memorial Institute under Contract DE-AC06-76RLO 1830 .

Associate editor: Jacques Schott

\section{References}

Burns, P.C., Miller, M.L., Ewing, R.C., 1996. $\mathrm{U}^{6+}$ minerals and inorganic phases: a comparison and hierarchy of crystal structures. The Can. Mineralogist 34, 845-880.

Burns, P.C., Finch, R.J., 1999. Uranium: Mineralogy, Geochemistry and the Environment. Mineralogical Society of America, Washington, DC.

Catalano, J.G., Heald, S.M., Zachara, J.M., Brown, G.E.J., 2004 Spectroscopic and diffraction study of uranium speciation in contaminated vadose zone sediments from the Hanford site, Washington. Env. Sci. Tech. 38, 2822-2828.

Davies, C.W., 1962. Ion Association. Butterworths, Washington, DC.

Felmy, A.R., Xia, Y., Wang, Z., 2005. The solubility product of $\mathrm{NaUO}_{2} \mathrm{PO}_{4} \cdot \mathrm{H}_{2} \mathrm{O}$ determined in phosphate and carbonate solutions. Radiochim. Acta 93, 401-408.

Giammar, D.E., Hering, J.G., 2002. Equilibrium and kinetic aspects of soddyite dissolution and secondary phase precipitation in aqueous suspension. Geochim. Cosmochim. Acta 66, 3235-3245.

Grenthe, I., Fuger J., Konings, R.J.M., Lemire, R.J., Muller, A.B., Nguyen-Trung, C., Wanner, H., 1992. Chemical Thermodynamics. Vol. 1, Chemical Thermodynamics of Uranium. OECD-NEA, Elsevier.

Guillaumont, R., Fanghanel, T., Neck, V., Fuger, J., Palmer, D.A., Grenthe, I., Rand, M.H., 2003. Update on the Chemical Thermodynamics of Uranium, Neptunium, Plutonium, Americium, and Technetium. Elsevier B.V., Amsterdam, The Netherlands.

Honea, R.M., 1961. New data on boltwoodite, an alkali uranyl silicate. Am. Mineral. 46, 12.

Liu, C., Zachara, J.M., Qafoku, O., McKinley, J.P., Heald, S.M., Wang, Z., 2004. Dissolution of uranyl microprecipitates in subsurface sediments at Hanford Site, USA. Geochim. Cosmochim. Acta 68, 4519-4537.

Mckinley, J.P., Heald, S.M., Zachara, J.M., Resch, C.T., 2002, The identification of uranium bearing phases by X-ray microprobe, electron microprobe, and scanning electron microscopy. In: Field Investigation Report for Waste Management Area B-BX-BY. River Protection Project (RPP) RPP-10098, Prepared for the Office of River Protection by CH2M Hill Hanford Group, Richland, WA, pp. D122-D129.

Nguyen, S.N., Silva, R.J., Weed, H.C., Andrews Jr., J.E., 1992. Standard Gibbs free energies of formation at the temperature $303.15 \mathrm{~K}$ of four uranyl silicates: soddyite, uranophane, sodium boltwoodite, and sodium weeksite. J. Chem. Thermodyn. 24, 359-376.

NIST, 2001. NIST critically selected stability constants of metal complexes database, Version 6.0 for Windows. US Department of Commerce, Technology Administration, National Institute of Standards and Technology, Standard Reference Data Program, Gaithersburg, MD 20899.

Perez, I., Casas, I., Martin, M., Bruno, J., 2000. The thermodynamics and kinetics of uranophane dissolution in bicarbonate test solutions. Geochim. Cosmochim. Acta 64, 603-608.

Perez, I., Casas, I., Torreo, M.E., Cera, E., Duro, L., Bruno, J., 1997. Dissolution studies of soddyite as a long-term analogue of the 
oxidative alteration of the spent nuclear fuel matrix. Mat. Res. Soc. Symp. Proc. 465, 565-572.

Pitzer, K.S., 1973. Thermodynamics of electrolytes. I. Theoretical basis and general equations. J. Phys. Chem. 77, 268.

Pitzer, K.S., 1991. Ion interaction approach: Theory and data correlation in activity coefficients. In: Electrolyte Solutions, 2nd ed. CRC Press, Boca Raton, p. 75.

Pokrovsky, O.S., Schott, J., 2000a. Fosterite surface compositions in aqueous solutions: a combined potentiometric, electrokinetic, and spectroscopic approach. Geochim. Cosmochim. Acta 64, 3299-3312.

Pokrovsky, O.S., Schott, J., 2000b. Kinetics and mechanism of forsterite dissolution at $25^{\circ} \mathrm{C}$ and $\mathrm{pH}$ from 1 to 12. Geochim. Cosmochim. Acta 64, 3313-3325.

Riley, R.G., Zachara, J.M., 1992. Chemical contaminants on DOE lands and election of contaminant mixtures for subsurface science research. U.S. Department of Energy, Office of Energy Research, Washington, DC.

Scofield, J.H., 1976. Hartree-Slater subshell photoionizatrioncross-sections at 1254 and $1457 \mathrm{eV}$. J. Electron Spectrosc. 8, 129-137.
Serne, R.J. et al., 2002. Characterization of Vadose zone sediment: Borehole 299-E33-46 near tank $B-110$ in the $B-B X-B Y$ waste management area. Pacific Northwest National Laboratory, Richland, WA.

Steward, S.A., Mones, E.T., 1997. Comparison and modeling of aqueous dissolution rates of various uranium oxides. Mat. Res. Soc. Symp. Proc. 465, 557-564.

Vochten, R., Blaton, N., Peeters, O., VanSpringel, K., VanHaverbeke, L., 1997. A new method of synthesis of boltwoodite and of formation of sodium boltwoodite, uranophane, sklodowskite and kasolite from boltwoodite. Can. Miner. 35, 735-741.

Wang, Z., Zachara, J.M., Yantasee, W., Gassman, P.L., Liu, C., Joly, A.G., 2004. Cryogenic laser induced flurorescence characterization of U(VI) in Hanford vadose zone pore waters. Environ. Sci. Tech. 38, 5591-5597.

Wang, Z., Zachara, J.M., Gassman, P.L., Liu, C., Qafoku, O., Catalano, J.G., 2005. Fluorescence spectroscopy of U(VI)-silicates and U(VI)-contaminated Hanford sediment. Geochim. Cosmochim. Acta 69, 1391-1403. 